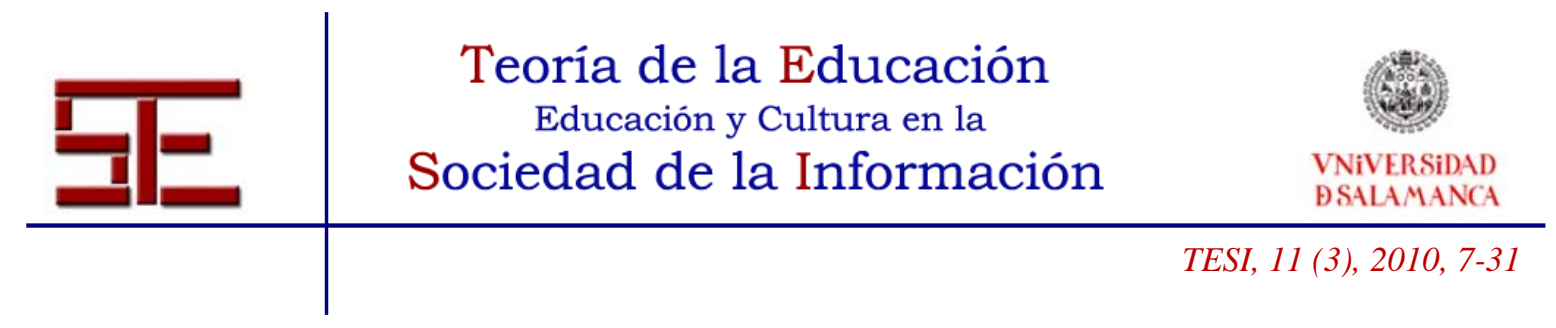

\title{
BUENAS PRÁCTICAS DE AULAS VIRTUALES EN LA DOCENCIA UNIVER- SITARIA SEMIPRESENCIAL
}

\section{Resumen:}

En este artículo presentamos el diseño y resultados de un estudio realizado en la Universidad de La Laguna (ULL) destinado a identificar buenas prácticas de aulas virtuales en la docencia universitaria desarrolladas bajo la modalidad de blended learning o enseñanza semipresencial. El estudio se desarrolló en el primer trimestre del año 2008 y analizó una importante muestra de las aulas virtuales $(\mathrm{N}=107)$ existentes en el Campus Virtual de dicha universidad en el periodo 2005-07. Se seleccionaron seis ejemplos de aulas virtuales, clasificados por campos científicos, caracterizadas por la incorporación de recursos de información, de comunicación y de aprendizaje experiencial.

Palabras clave:

Buenas prácticas, innovación educativa, tecnología de la información y la comunicación, experiencias TIC, aulas virtuales.

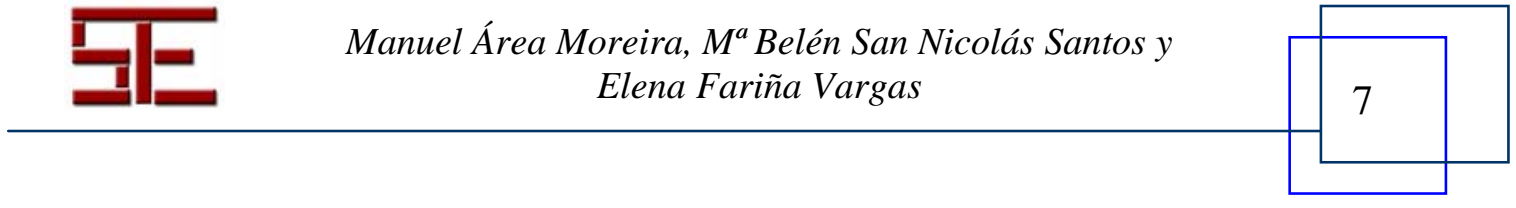




\title{
GOOD PRACTICES FOR VIRTUAL CLASSROOM IN UNIVERSITARY BLENDED LEARNING
}

\begin{abstract}
:
We present the design and results of a study conducted at the University of La Laguna (ULL) to identify best practices in virtual classrooms in Higher Education developed in the form of blended learning. The study was conducted in the first quarter of 2008 and analyzed a large sample of virtual classrooms $(\mathrm{N}=107)$ in the Virtual Campus of the University during the period 2005-07. This article presents six examples of virtual classrooms by scientific fields characterized by the incorporation of information resources, communication and experiential learning.
\end{abstract}

Key words:

Good practices, educational innovation, information and comunication Technologies, ICT experiences, virtual classroom.

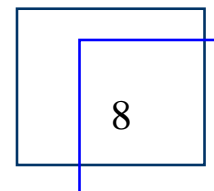




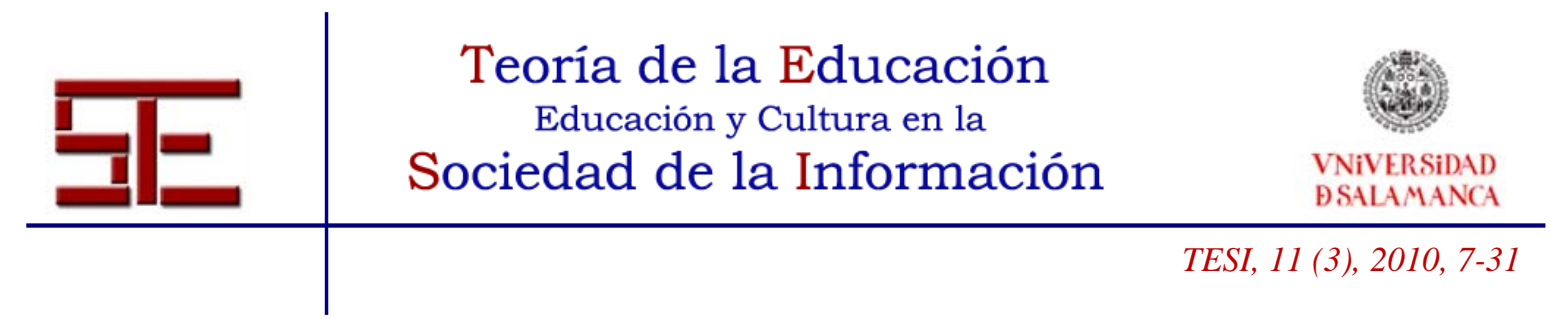

\section{BUENAS PRÁCTICAS DE AULAS VIRTUALES EN LA DOCENCIA UNI- VERSITARIA SEMIPRESENCIAL}

Fecha de recepción: 10/02/2009; fecha de aceptación: 20/12/2009; fecha de publicación: 28/02/10

Manuel Area Moreira

manarea@ull.es

Universidad de La Laguna

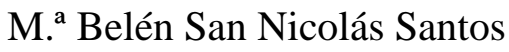

bsannico@ull.es

Universidad de La Laguna

Elena Fariña Vargas

efarina@ull.es

Universidad de La Laguna

\section{1.- UNA APROXIMACIÓN A LOS MODELOS DE USO DE AULAS VIRTUA- LES EN LA DOCENCIA UNIVERSITARIA}

Tradicionalmente el e-learning se ha vinculado con la educación a distancia (Barajas y Álvarez, 2005; García; Ruiz y Domínguez, 2007; Barberá, 2008; Landeta, 2008). Evidentemente, las aulas virtuales de e-learning son poderosas herramientas que han permitido incrementar la calidad de los procesos formativos a distancia, y los estudios ofertados por este tipo de instituciones educativas han sido pioneros en el desarrollo del elearning. Sin embargo hoy en día los recursos educativos distribuidos a través de la Web -bien abiertos y públicos, bien en espacios cerrados virtuales- también son empleados en diversidad de situaciones presenciales. De este modo, podemos identificar tres grandes modelos de utilización de los recursos de Internet, en general, y de las aulas virtuales de forma más específica en la docencia en función del grado de presencialidad o distancia en la interacción entre profesor y alumnado (Area y Adell, 2009). Estos tres grandes modelos a los que nos referimos son los siguientes:

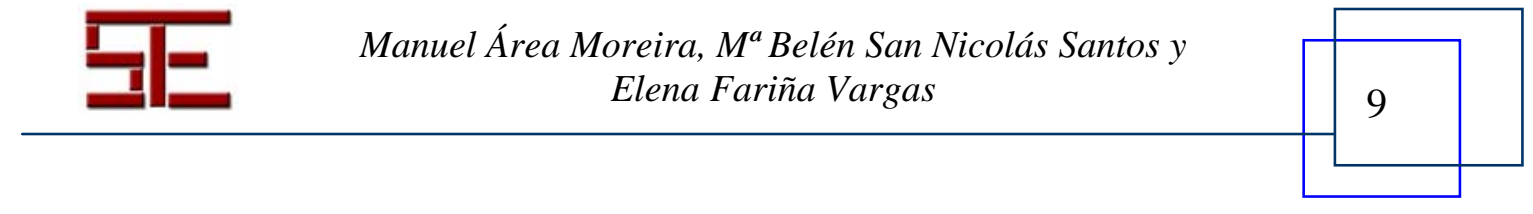




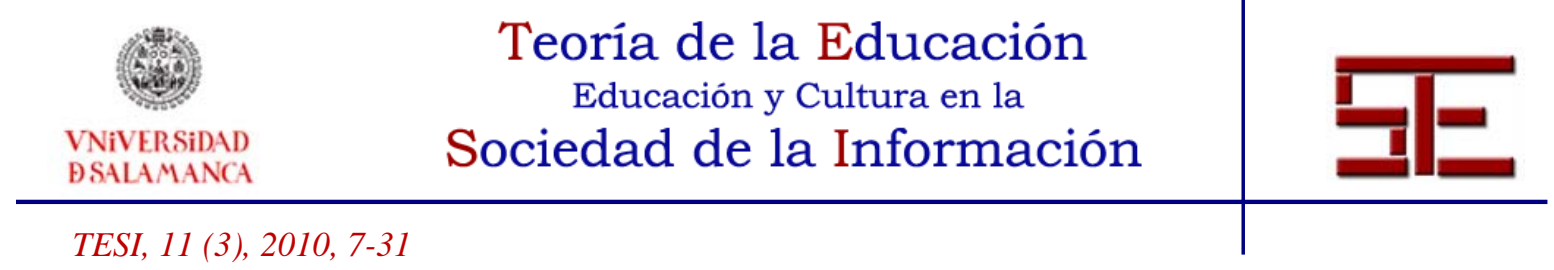

\section{1.- Modelo de docencia presencial con Internet: el aula virtual como complemento o recurso de apoyo}

Este modelo representa el primer nivel o ámbito inicial y básico de uso de las aulas virtuales por la mayor parte del profesorado que comienza a explorar el uso de Internet en su docencia. Consiste en plantear el aula virtual como un apéndice o anexo de la actividad docente tradicional. Es decir, el profesor no cambia ni los espacios de enseñanza que habitualmente utiliza, ni el tipo de actividades que plantea a sus estudiantes ni las formas que emplea de comunicación con los mismos. El aula virtual en este modelo se convierte en un recurso más que tiene el profesor a su alcance junto con los de que ya dispone: pizarra, laboratorio, seminario o cañón de proyección multimedia.

Normalmente el uso de estas aulas virtuales son para transmitir información: es decir, colgar los apuntes y otros documentos de estudio de la asignatura, el programa de las mismas, los horarios de tutorías en el despacho o las calificaciones de los trabajos y exámenes de los estudiantes. El aula virtual en este modelo es un híbrido entre la fotocopiadora y el tablón de anuncios ya que lo que prima es la información. Por otra parte, apenas existe comunicación entre los estudiantes y entre éstos y el docente. Asimismo no es habitual el plantear tareas o actividades para que sean cumplimentadas a través del aula virtual.

En síntesis, en este modelo de uso de aula virtual lo relevante sigue siendo el proceso de enseñanza presencial del aula física (exposiciones magistrales, debates, prácticas de laboratorio...). El profesor sigue haciendo lo de siempre, pero apoyado en un recurso tecnológico.

1.2.- Modelo de docencia semipresencial: el aula virtual como espacio combinado con el aula física o blended learning

Este segundo modelo se caracteriza por la yuxtaposición o mezcla entre procesos de enseñanza-aprendizaje presenciales con otros que se desarrollan a distancia mediante el uso del ordenador. Es denominado como blended learning (b-learning), enseñanza semipresencial o docencia mixta. El aula virtual no sólo es un recurso de apoyo a la enseñanza presencial, sino también un espacio en el que el docente genera y desarrolla acciones diversas para que sus alumnos aprendan: formula preguntas, abre debates, plantea trabajos... En este modelo se produce una innovación notoria de las formas de trabajo, comunicación, tutorización y procesos de interacción entre profesor y alumnos.

La enseñanza semipresencial o b-learning requiere que el docente planifique y desarrolle procesos educativos en los que se superponen tiempo y tareas que acontecen bien en el aula física, bien en el aula virtual sin que necesariamente existan interferencias entre unas y otras. Asimismo el profesor debe elaborar materiales y actividades para que el estudiante las desarrolle autónomamente fuera del contexto clase tradicional. Evidente-

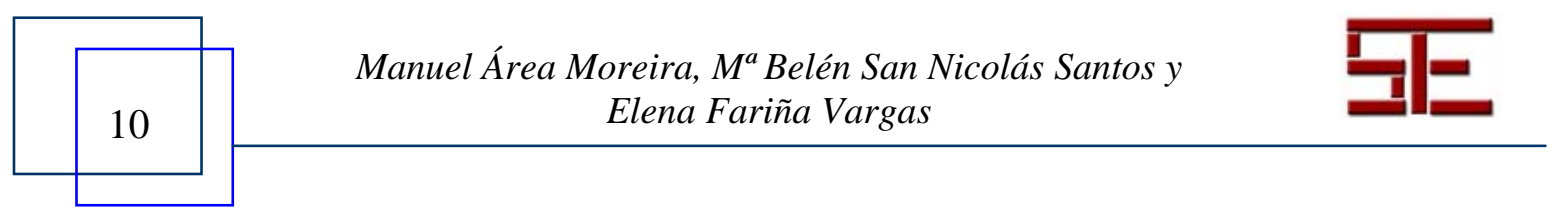




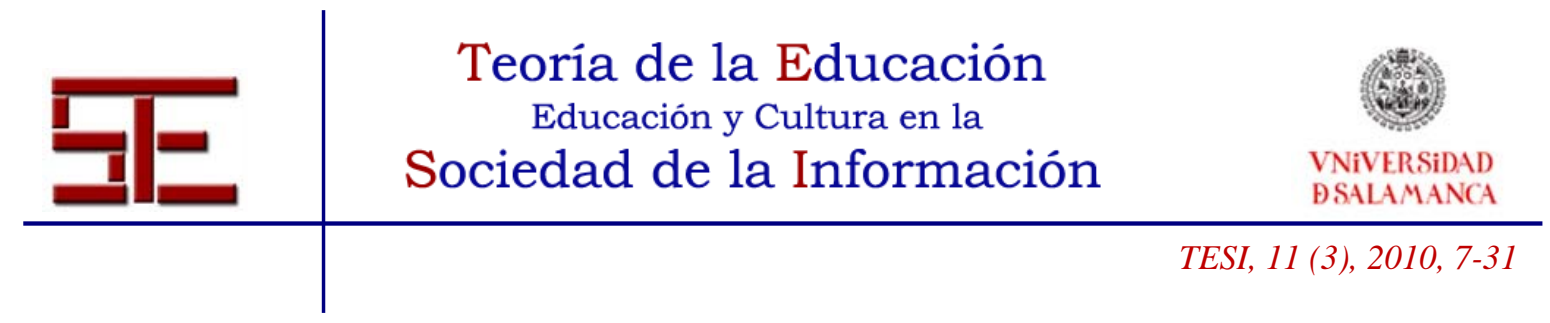

mente dentro de este modelo existen variantes o grados en función del peso temporal y de trabajo distribuido ente situaciones presenciales y virtuales.

\section{3.- Modelo de docencia a distancia: el aula virtual como único espacio educativo}

El tercer modelo representa la actualización de la modalidad clásica de educación a distancia, pero desarrollada en entornos exclusivamente virtuales. Apenas se produce contacto físico o presencial entre profesor y estudiantes ya que la mayor parte de las acciones docentes, comunicativas y de evaluación tienen lugar en el marco del aula virtual. Este modelo es el que tradicionalmente se conoce como e-learning, aunque las distinciones entre el b-learning y el e-learning son cada vez más difusas.

En esta modalidad educativa el material o recursos didácticos multimedia cobran una especial relevancia ya que el proceso de aprendizaje de los estudiantes estará guiado, en su mayor parte, por los mismos. Asimismo la interacción comunicativa dentro del aula virtual es un factor clase y sustantivo para el éxito del estudiante. Requiere, para su desarrollo pleno, una organización institucional fuerte y con relevancia que oferte titulaciones on line (asignaturas, cursos, máster, doctorado) a través de campus virtuales gestionados por un equipo de expertos y administradores. Actualmente existen universidades completamente on line (uno de los ejemplos más conocidos es la UOC-Universitat Oberta de Catalunya), y numerosos campus virtuales gestionados por universidades que tradicionalmente han realizado su docencia de forma presencial (acceso a campus virtuales de las universidades españolas).

\section{2.- EL CONCEPTO DE “BUENAS PRÁCTICAS” CON AULAS VIRTUALES EN LA DOCENCIA UNIVERSITARIA SEMIPRESENCIAL}

Previamente a la selección y descripción de las buenas prácticas de e-learning universitario $^{1}$ en el contexto de docencia semipresencial, es conveniente realizar una aproximación al concepto de buenas prácticas. Este término está directamente relacionado con los procesos de innovación didáctica por lo que es necesario definirlo y contextualizarlo para el ámbito educativo.

El término "buenas prácticas" no es un término nuevo. Hace ya veinte años atrás Chickering y Gamson (1987) establecieron siete principios que configuraban una buena práctica educativa:

- Promueve las relaciones entre profesores y alumnos.

- Desarrolla dinámicas de cooperación entre los alumnos.

\footnotetext{
${ }^{1}$ Este estudio forma parte de una investigación más amplia realizada en el Campus Virtual de La Universidad de La Laguna, durante los cursos 2005-2006 y 2006-2007. Se han seleccionado una serie de prácticas innovadoras en diferentes campos científicos.
}

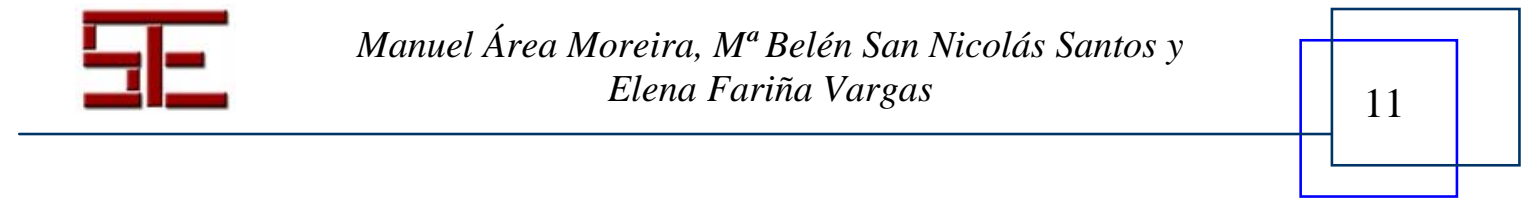




\section{\begin{tabular}{ccc}
$\substack{\text { Teoria de la Educación } \\
\text { ENiVERSIDAD } \\
\text { BSALAMANCA }}$ & $\begin{array}{c}\text { Tdución y Cultura en la } \\
\text { Sociedad de la Información }\end{array}$ \\
\hline TESI,11 (3), 2010, 7-31 & & \\
\hline
\end{tabular}}

- Aplica técnicas activas para el aprendizaje.

- Permite procesos de retroalimentación.

- Enfatiza el tiempo de dedicación a la tarea.

- Comunica altas expectativas.

- Respeta la diversidad de formas de aprender.

La UFI (University for Industry) del Reino Unido, en el año 1998, estableció siete niveles de buenas prácticas en la enseñanza a distancia basada en redes (Stephenson, 2005):

- Ofrecer tiempos, espacios, tranquilidad y estilos de aprendizaje que respondan a las necesidades de los alumnos.

- Dar información clara que ayude a tomar la mejor elección sobre el programa formativo y tener el control sobre él.

- Dar materiales relevantes para el interés del propio trabajo que involucren prácticas, ejemplos y ejercicios.

- Permitir monitorizar el progreso y grabarlo para su consulta durante el proceso, no al final.

- Dar facilidades de acceso al soporte de especialistas que se necesite.

- Propiciar el diálogo entre personas que estudian las mismas cosas.

- Dar la oportunidad al estudiante de elegir la intensidad de su aprendizaje hasta donde marque la ambición de sus objetivos.

En este sentido, la identificación de buenas prácticas permite aprender de las mismas, contextualizarlas y mejorar nuestras propias prácticas; este análisis crítico de unos determinados casos hace posible que puedan ser transferidos a otros contextos. Epper y Bates (2004) citan las siguientes características para referirse a las buenas prácticas:

- Contribuyen a mejorar el desempeño de un proceso.

- Responden a una experiencia sistematizada, documentada y experimentada.

- Su diseño se realiza desde un enfoque innovador.

- Que aplican métodos de excelencia basados en la innovación.

- La categoría de buenas prácticas las hace extrapolables a otros contextos.

De manera más reciente De Pablos y González (2007) realizan las siguientes aportaciones al concepto de buenas prácticas:

- Como una manera de modelizar y ejemplificar una actividad realizada con resultados satisfactorios. El desarrollo de una buena práctica responde a una visión compartida de "querer avanzar". Desde esta perspectiva las buenas prácticas son el mejor escaparate de un contexto específico.

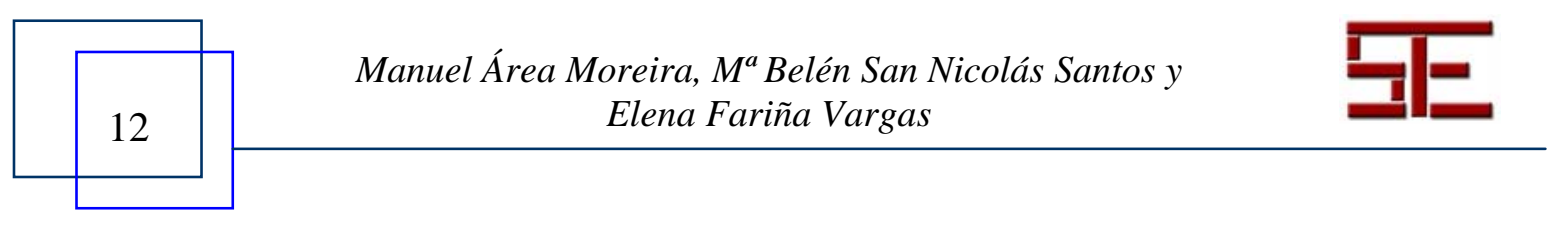




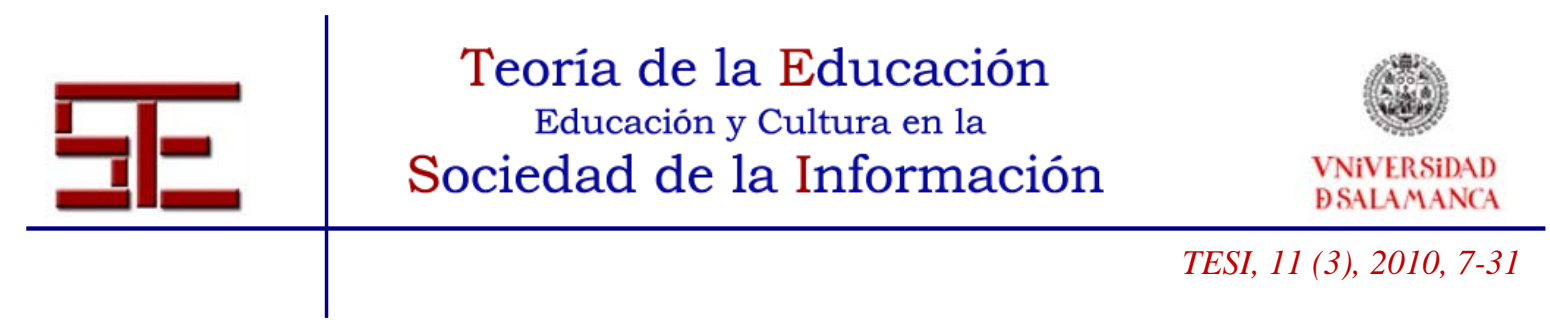

- Como reflejo/producto de la identidad de un contexto; en este caso sería una buena herramienta para gestionar las diferencias y sacar a la luz lo singular y lo específico de ese contexto.

- Como instrumento de control de quien diseña las políticas públicas para legitimar esas políticas.

- Como instrumento para gestionar el cambio en las organizaciones.

- El término de "buenas" les otorga carácter de transferibilidad y exportabilidad.

- Las "buenas prácticas" resisten a las dificultades, responden a procesos de excelencia. Los retos, fracasos y éxitos experimentados en la implementación de una práctica forma parte de la definición de la misma como buena.

Podemos concluir por tanto que la identificación y selección de buenas prácticas, así como su difusión a la comunidad educativa, permitirán optimizar o mejorar los resultados futuros.

\section{3.- EL CONTEXTO DEL ESTUDIO REALIZADO: EL CAMPUS VIRTUAL DE LA UNIVERSIDAD DE LA LAGUNA}

Antes de proceder a presentar el diseño y resultados del estudio realizado sobre buenas prácticas de aulas virtuales en la docencia universitaria desarrolladas bajo la modalidad de blended learning o enseñanza semipresencial quisiéramos describir el origen y evolución del Campus Virtual de la Universidad de La Laguna donde están insertadas las aulas virtuales analizadas. El estudio se desarrolló en el primer trimestre del año 2008 y analizó una importante muestra de las aulas virtuales $(\mathrm{N}=107)$ existentes en dicho campus en el periodo 2005-07.

\section{1.- La primera versión del Campus Virtual de la ULL (periodo 2001-2004)}

La creación de la primera versión del Campus Virtual de la Universidad de la Laguna (http://www.campusvirtual.ull.es) se realizó en el año 2001². La tarea de creación y desarrollo de este campus virtual así como de mantenimiento del servidor fue implementada por el equipo de investigadores del Laboratorio de Educación y Nuevas Tecnologías de la Universidad de la Laguna (Edullab). En dicho campus virtual (véase la Figura 1) se tenía acceso, entre otros, a una serie de cursos de doctorado on line diseñados bajo la plataforma WebCT, así como a distintos sitios web de asignaturas concretas desarrollados por el profesorado de la ULL en formato HTML clasificados por campos científi-

\footnotetext{
${ }^{2}$ El campus virtual fue fruto del Proyecto denominado "Creación de un Laboratorio de Educación y Nuevas Tecnologías de la Universidad de La Laguna (ULL) para la formación docente y desarrollo de materiales didácticos multimedia para el Tercer Ciclo”. Financiado con fondos de la Secretaría de Estado de Educación y Universidades del MEC (Proyecto n. ${ }^{\circ}$ AFC2000-0028-IN) e impulsado por los Vicerrectorados de Servicios Generales y de Nuevas Titulaciones y Calidad Educativa.
}

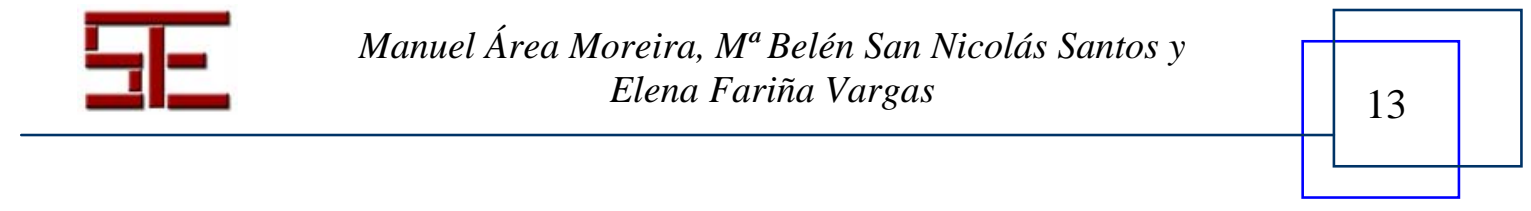




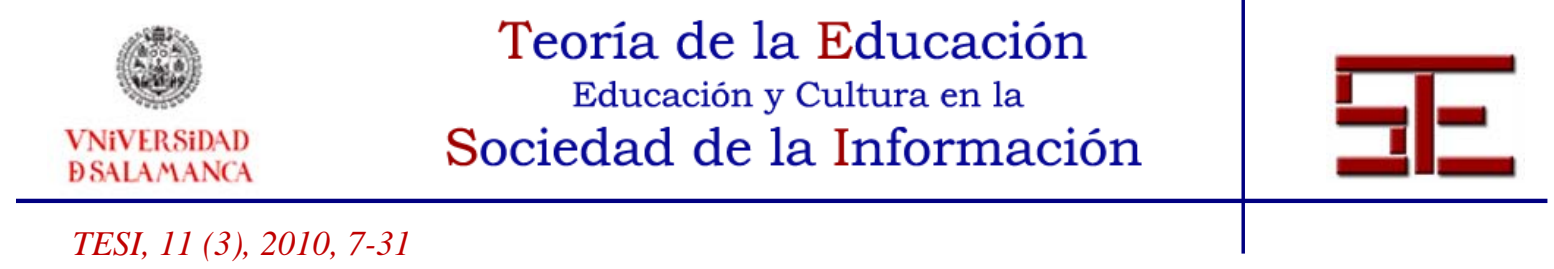

cos. Una descripción más detallada de esa primera versión del campus virtual de la ULL puede consultarse en Area et al. (2002).

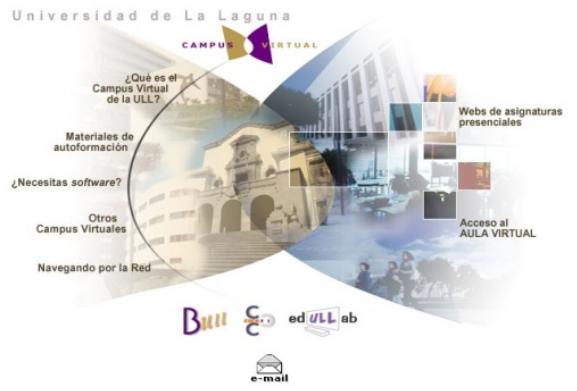

Figura 1.Versión inicial del Campus Virtual de la ULL (2001)

Durante este periodo, la ULL no ofertó institucionalmente ningún espacio, recurso o portal para la docencia virtual en nuestra universidad. Ello provocó que aquellos profesores sensibilizados con la necesidad de utilizar las TIC en la docencia buscaran soluciones paralelas y creadas ad hoc, al margen del equipo de gobierno. De este modo surgieron en distintos servidores de la ULL campus virtuales autogestionados por un equipo o grupo y que respondían a las necesidades particulares del profesorado participante. En el año 2004 desapareció este portal del campus virtual de la ULL por falta de financiación.

3.2.- El resurgimiento del campus virtual de la ULL: los proyectos piloto de docencia virtual y la creación de la UDV (periodo 2005-07)

En diciembre de 2005 se aprobó en la Junta de Gobierno de la ULL la creación de la UDV (Unidad de Docencia Virtual). Paralelamente se realizó la primera convocatoria de proyectos de docencia virtual destinados a asignaturas de cualquier titulación oficial de la ULL que se impartiese en el segundo cuatrimestre del año 2005-06. El Vicerrectorado de Planes de Estudios y Títulos Propios fue el encargado de dicha convocatoria.

Este nuevo campus virtual creado en el año $2006^{3}$ fue desarrollado bajo la plataforma de software libre MOODLE y el mantenimiento del mismo junto con su servidor fue asumido por la Fundación Universidad-Empresa de la ULL (véase Figura 2). Se crearon en el mismo 45 aulas virtuales.

\footnotetext{
${ }^{3}$ Puede verse una copia de dicha versión del Campus Virtual de la ULL (2006) en la siguiente dirección:
} http://w3.feu.ull.es/cv05-06/.

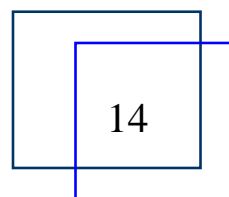

Manuel Área Moreira, $M^{a}$ Belén San Nicolás Santos y Elena Fariña Vargas 


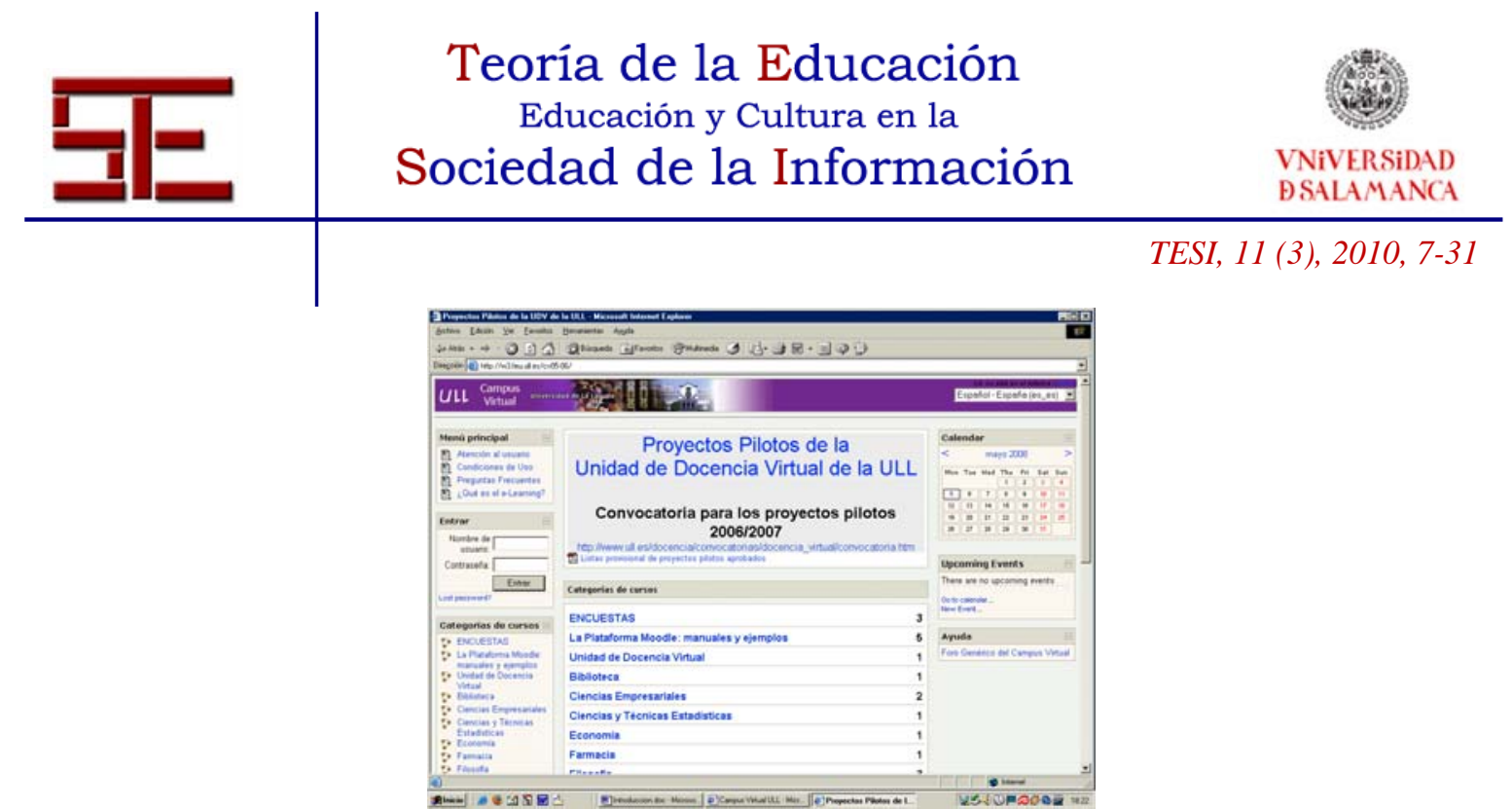

Figura 2. Nueva versión del Campus Virtual ULL (2006)

En el curso siguiente (2006-07) se volvió a realizar dicha convocatoria de proyectos piloto $^{4}$ para la docencia virtual procediéndose a abrir un nuevo espacio virtual para alojar dichas aulas. Este campus virtual era similar al creado el curso anterior (véase Figura 2) ya que también estaba desarrollado bajo la plataforma MOODLE y administrado por el mismo equipo técnico perteneciente a la Fundación Universidad-Empresa. Se crearon un total de 141 aulas virtuales.

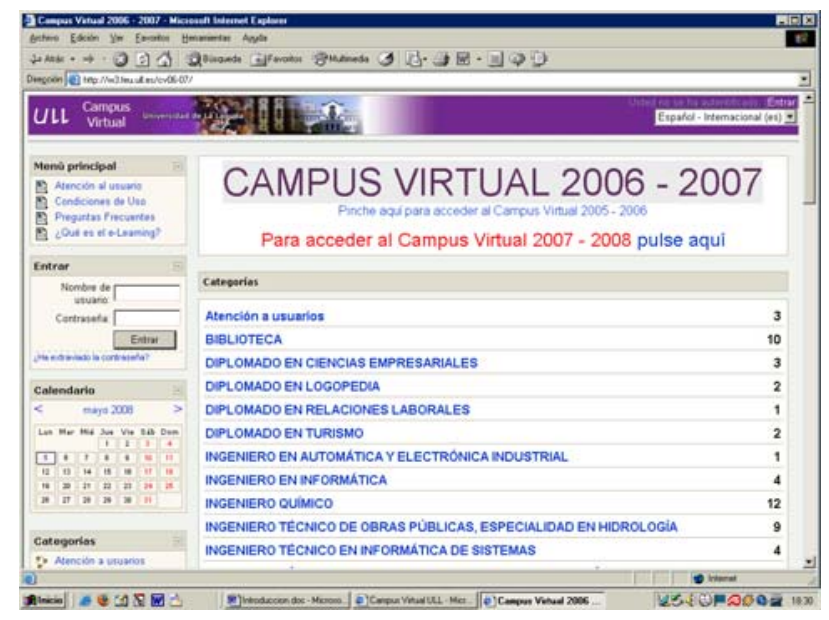

Figura 3. Campus Virtual ULL (2006-07)

3.3.- La situación actual: la nueva etapa del Campus Virtual de la ULL (curso 2007-08)

${ }^{4}$ Convocatoria: http://www.ull.es/docencia/convocatorias/docencia_virtual/convocatoria.htm.

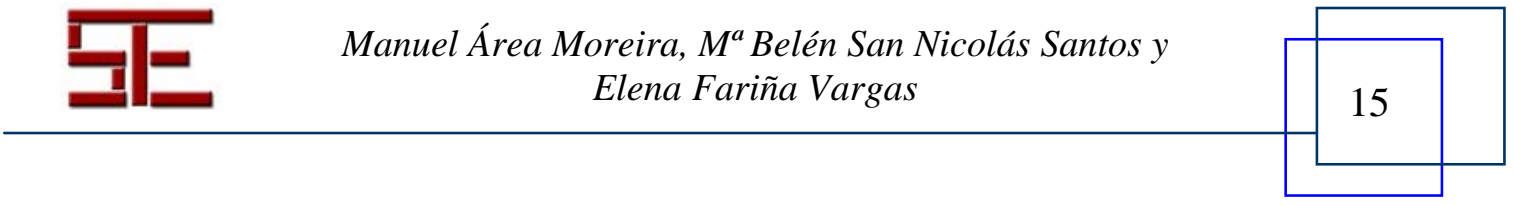




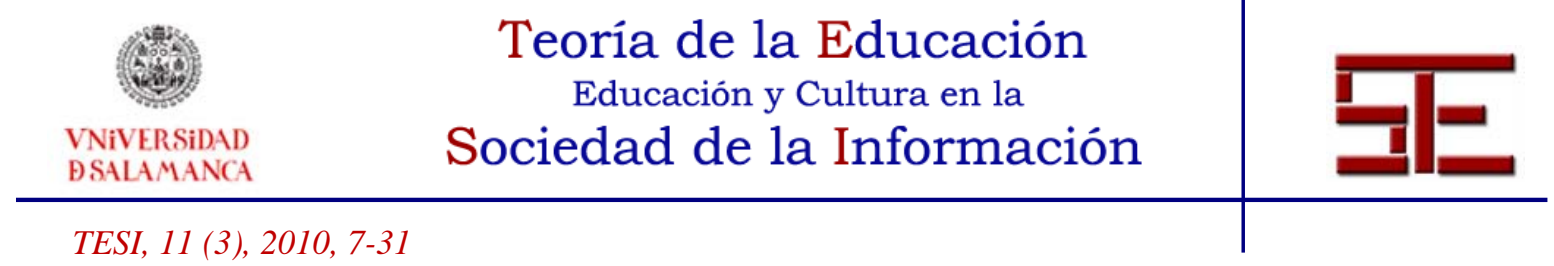

Al comienzo del curso 2007-08 se abre una nueva etapa en campus virtual de la ULL. El servidor deja de estar alojado y gestionado por la FUE para ser asumido por la Unidad de Docencia Virtual (UDV). Asimismo se cambia la interface del CV (ver Figura 4), y se oferta la creación de nuevas aulas virtuales más allá de las específicamente abiertas para la convocatoria de proyectos piloto de docencia virtual.

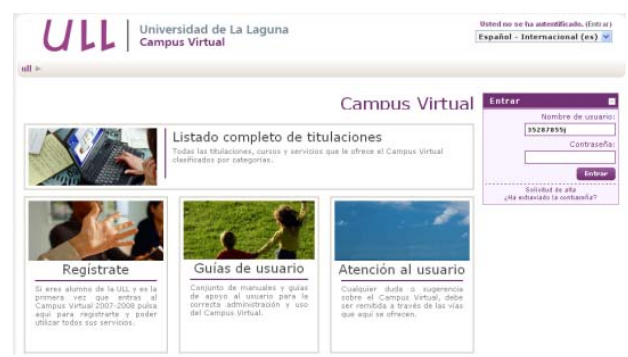

Figura 4. Versión actual del Campus Virtual de la ULL (2008)

Por otra parte, la UDV desarrolla un espacio virtual propio para la oferta de los distintos servicios de apoyo al profesorado en la implementación de proyectos y experiencias de docencia virtual (véase Figura 5).

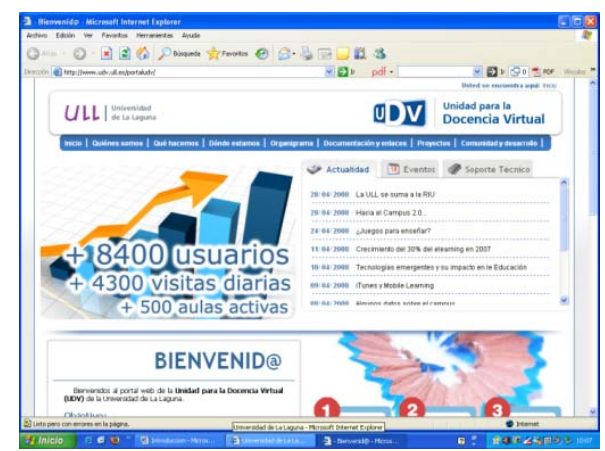

Figura 5. Nuevo sitio Web de la UDV (2008)

\section{4- DISEÑO DE LA INVESTIGACIÓN}

Este estudio surge con la intención de realizar una evaluación inicial, a modo de diagnóstico, en torno a la calidad tanto educativa (contenidos, actividades, evaluación...) como técnico-organizativa (diseño gráfico, recursos incorporados, estructura...) de las aulas virtuales creadas por el profesorado en el Campus Virtual de la ULL durante los cursos académicos 2005-06 y 2006-07. Además nos planteamos explorar si, en el periodo aludido, existían diferencias en función de los campos científicos y titulaciones.

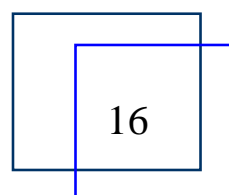

Manuel Área Moreira, $M^{a}$ Belén San Nicolás Santos y Elena Fariña Vargas 


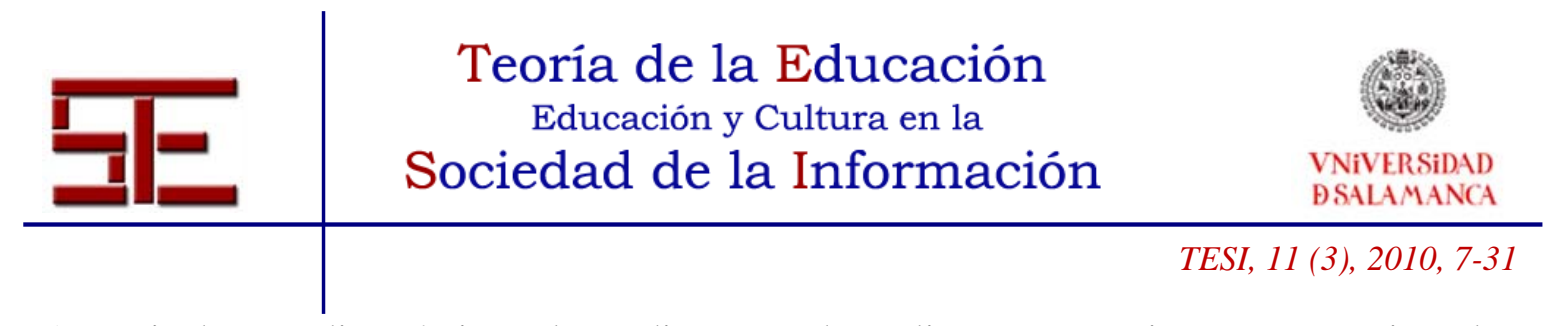

A partir de este diagnóstico, el estudio pretende realizar sugerencias y aportar ejemplos de aulas virtuales innovadoras, a través de las cuales se promueva la mejora e innovación de la docencia en estos espacios.

\section{1.- Objetivos}

El estudio de análisis de las aulas virtuales del Campus Virtual de la ULL fue realizado, entre otros, con la intención de:

- Identificar aquellas aulas virtuales que fueran ejemplos de buenas prácticas pedagógicas (al menos, en el diseño y desarrollo de las distintas dimensiones del entorno virtual).

- Destacar algunas prácticas concretas en las aulas virtuales que supongan ejemplos de innovación pedagógica en el ámbito universitario en distintos campos o ramas científicas y que pudieran emplearse como referentes para la formación del profesorado.

\section{2.- Muestra}

Para la realización del estudio se ha tomado como población el número total de aulas virtuales existentes en el Campus Virtual de la ULL durante los cursos 2005-06 y 2006$07(\mathrm{~N}=186)$. Sin embargo, para el análisis cualitativo se ha realizado una selección de las aulas virtuales quedando la muestra en 117 aulas.

De ese total de 117 aulas analizadas, en función de los criterios de calidad empleados, hemos seleccionado seis aulas virtuales que son representativas de buenas prácticas y que se corresponden a los siguientes campos científicos y asignaturas:

\section{Ciencias Sociales y Jurídicas:}

- Derecho Político II (Licenciado en Derecho)

- Estructura Económica Mundial I (Licenciado en Administración y Dirección de Empresas)

- Las Tecnologías de la Información y Comunicación en Educación (Licenciado en Pedagogía)

\section{Ingeniería y Arquitectura:}

- Análisis Matemático IV (2005-06)

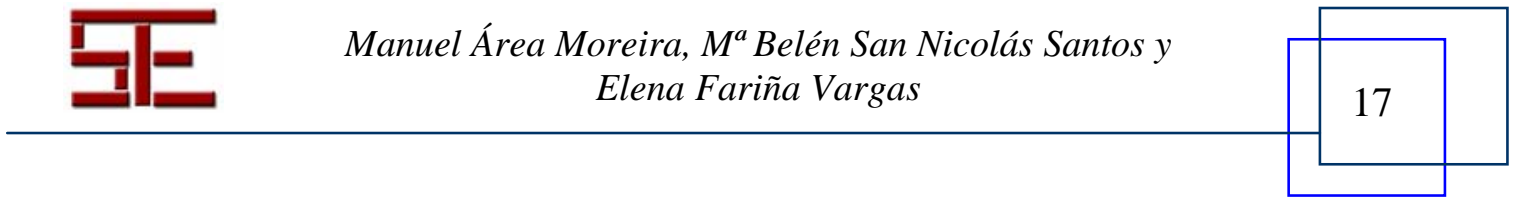




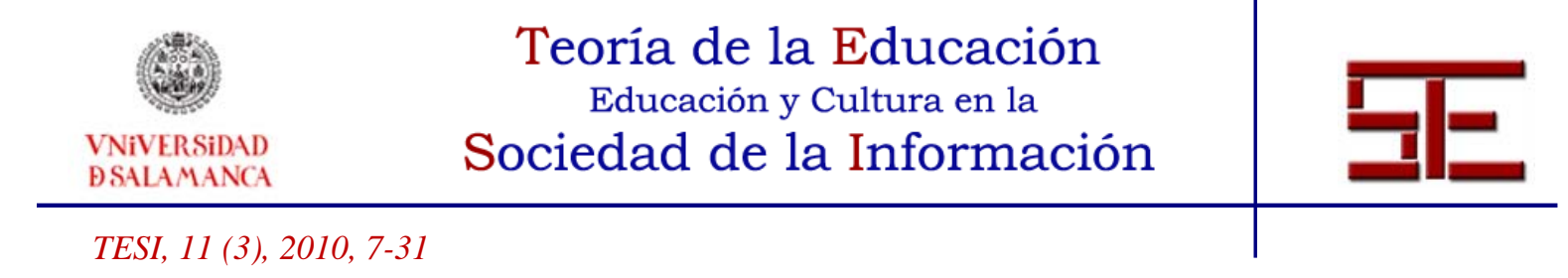

- Ingeniería Térmica (2006-07)

- Sistemas de Interacción Hombre-Máquina (2006-07)

\section{3.- Instrumento de observación de las aulas virtuales: dimensiones de análisis}

La metodología utilizada en el estudio consistió en la realización de un análisis descriptivo basado en observaciones de cada una de las aulas virtuales seleccionadas. El periodo de recogida y análisis de los datos se realizó a lo largo del primer trimestre del año 2008. Para ello se diseñó un instrumento específico para la observación de aulas virtuales similar a otros ya existentes (Barberá, 2008). Este instrumento nos permitió observar las siguientes dimensiones en cada una de las aulas virtuales: contenidos y recursos de información ofrecidos, actividades planteadas al alumnado, recursos de comunicación incorporados, organización didáctica y estructura del aula virtual, evaluación del aprendizaje, aspectos de diseño gráfico y el modelo pedagógico implícito.

Este instrumento, antes de su aplicación definitiva, fue presentado, discutido y revisado por el equipo técnico de la UDV (Unidad de Docencia Virtual). Asimismo se realizó una prueba piloto a una pequeña muestra de aulas virtuales para explorar las potencialidades del instrumento de observación, así como chequear las dificultades de aplicación del mismo. En función de los resultados obtenidos se reelaboró el instrumento definitivo. La aplicación del mismo se realizó sobre la totalidad de aulas existentes en el campus virtual de la ULL del curso 2005-06, y de una muestra de las aulas del campus virtual del curso 2006-07 ubicada en el servidor administrado por la Fundación Universidad-Empresa de la ULL.

Las dimensiones analizadas en cada aula virtual a través del instrumento de observación elaborado son las que se describen a continuación:

\section{DIMENSIONES DE ANÁLISIS DE LAS AULAS VIRTUALES}

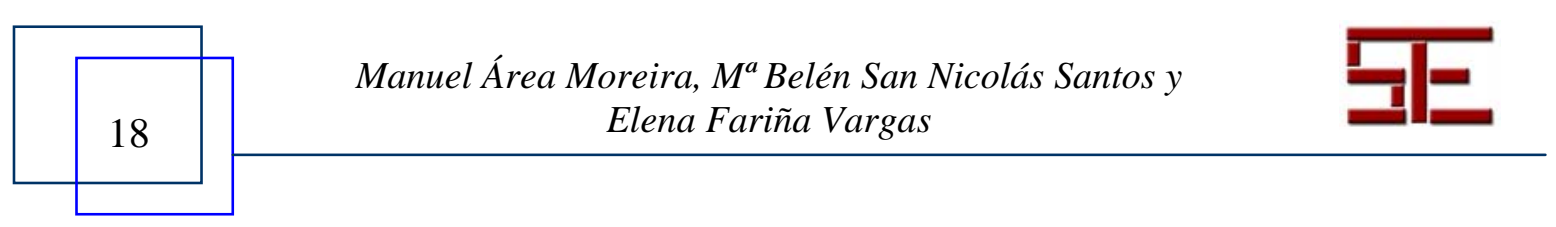



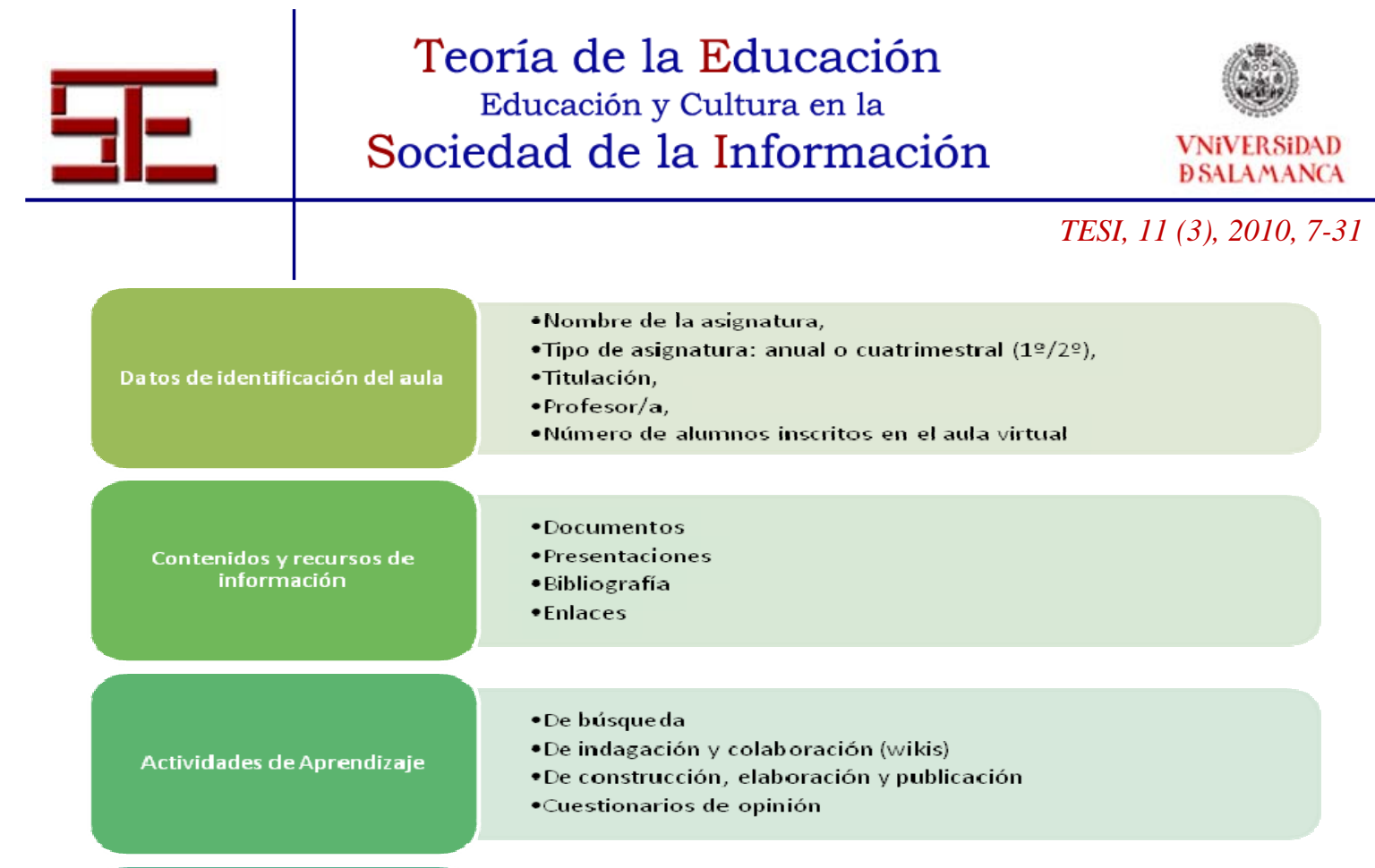

- De búsque da

- De indagación y colaboración (wikis)

- De construcción, elaboración y publicación

- Cuestionarios de opinión

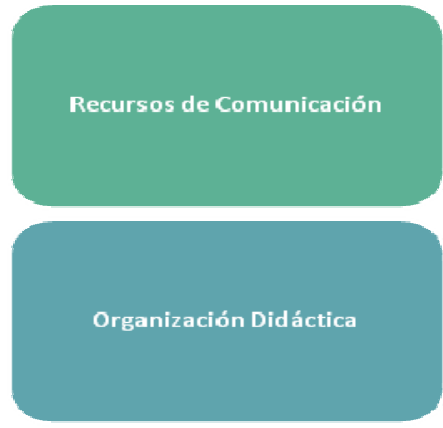

- Foros

-Tablón de anuncios

- Correo electrónico

-Tutorías

\section{- Calendario}

- Programa de la asignatura

- Estructura:Social (predominan los recursos de comunicación),

Temas (el contenido del aula se presenta en función de los

temas de la asignatura), Temporal (el contenido se presenta por semanas)

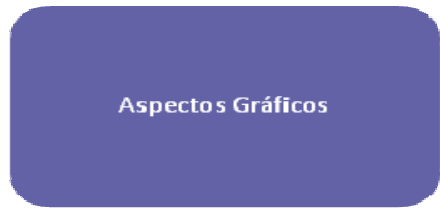

- Diseño y estructura gráfica

-Tipos de letra

- Imágenes

- Colores

\section{5.- CRITERIOS DE SELECCÓN DE LOS EJEMPLOS DE BUENAS PRÁCTI- CAS EN AULAS VIRTUALES}




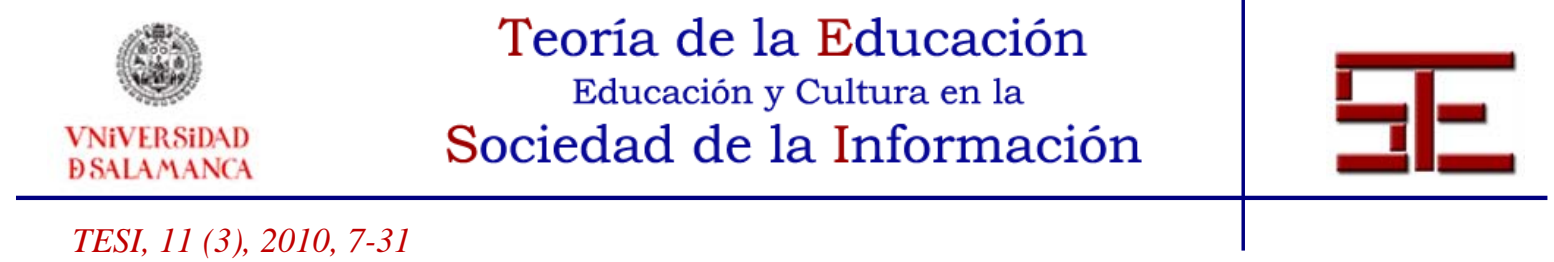

A continuación presentamos algunos ejemplos de lo que pudiéramos considerar, al menos desde un punto de vista pedagógico, buenas prácticas de aulas virtuales que han sido desarrolladas en el Campus Virtual de la ULL en el periodo analizado (2005-07). Para realizar dicha selección de ejemplos nos hemos basado en tres criterios:

1. El primero es que estas aulas se caracterizaran por la combinación y equilibro de las tres dimensiones que constituyen el modelo de análisis que hemos utilizado de docencia virtual (la dimensión informativa, la dimensión comunicativa y la dimensión experiencial). Con ello nos referimos a que estas aulas virtuales seleccionadas ofrecen:

a. Recursos de tipo informativo destinados a facilitar el acceso al conocimiento al alumnado mediante documentos de lectura, a modo de apuntes, para el estudio o reelaboración de los contenidos de la asignatura, presentaciones multimedia, esquemas, gráficos o mapas conceptuales, videoclips o animaciones, biblioteca digital, etc. Esta dimensión informativa se refiere, en consecuencia, a la exposición o presentación del saber que tiene que ser adquirido.

b. Recursos para la comunicación tales como foros de debate, tablones de noticias, mensajería interna. Estos recursos permiten que exista un importante flujo comunicativo entre los alumnos y entre éstos y su profesor. De este modo, el docente puede desempeñar acciones de tutorización bien individual o grupal, de seguimiento y evaluación continuada. Asimismo, estos recursos facilitan una mayor interacción y cohesión social entre los estudiantes de la clase.

c. Recursos para el aprendizaje experiencial en donde se le presentan a los alumnos actividades o tareas que tienen que realizar a través del aula virtual. Esta dimensión se refiere a que se crean situaciones de aprendizaje donde el alumno tiene que aprender a través de una experiencia o acción: por ejemplo, redactar un documento o informe, buscar información para construir una base de datos, planificar y ejecutar un proyecto, resolver un problema, analizar un caso, construir un videoclip, etc.

2. El segundo criterio es que estos ejemplos fueran representativos del mayor número de campos o áreas científicas. Por esta razón, se han seleccionado siete aulas virtuales que pertenecen a distintas ramas y titulaciones. Hemos evitado, en este sentido, seleccionar más de un ejemplo del mismo campo o titulación a pesar de que existen otros ejemplos valiosos.

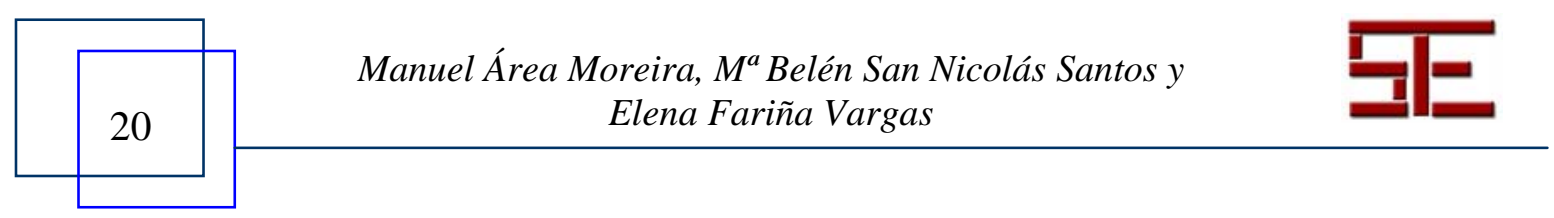




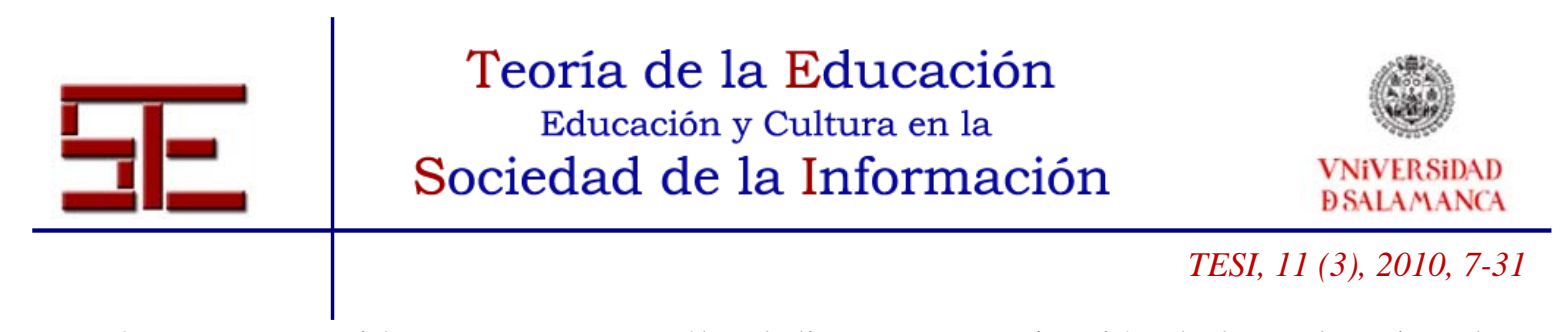

3. Hemos tenido en cuenta, no sólo el diseño u organización de las aulas virtuales, sino también la práctica y actuación desarrollada durante el periodo de docencia tanto por los estudiantes como por el docente. Es decir, hemos seleccionado aquellos ejemplos que se caracterizan porque el docente y sus alumnos han estado participando de modo activo y continuado dentro del aula virtual. En este sentido, estos ejemplos serían representativos de buenas prácticas de docencia semipresencial donde se produce una yuxtaposición entre tiempos y acciones desarrollados presencialmente y otros desarrollados en el espacio virtual.

\section{6.- RESULTADOS: SELECCIÓN DE EJEMPLOS DE BUENAS PRÁCTICAS DE AULAS VIRTUALES EN LA UNIVERSIDAD DE LA LAGUNA}

Después de aplicar el instrumento de análisis a la muestra de aulas virtuales $(\mathrm{N}=117)$ hemos seleccionado seis casos como representativos de buenas prácticas. Todas las aulas virtuales de las asignaturas que se presentan a continuación han sido consideradas como buenos ejemplos ya que en las mismas existe un equilibrio entre las dimensiones informativa, comunicativa y experiencial de la enseñanza en el sentido de que, por un lado, el profesor aporta documentos textuales en distintos formatos, presentaciones multimedia, esquemas, el programa de la asignatura, los temas... (es decir, recursos informativos para el estudio del contenido); por otra, propone diversas actividades que los alumnos deben cumplimentar a través del aula virtual (recursos para el aprendizaje experiencial) y, por último, se generan procesos de interacción social y comunicativa entre el docente y los estudiantes a través de foros, correo electrónico o chat (recursos de comunicación).

\section{Campo de Ciencias Sociales y Jurídicas}

\section{Asignatura: Derecho Político II (2006-2007)}

- Titulación en la que se imparte: Licenciado en Derecho

- Número de profesores en el aula: 1

- $\quad$ Número de estudiantes en el aula: 117

El aula virtual creada para la asignatura de Derecho Político II, en el curso académico 2006-07, es un espacio que reúne varios ejemplos de buenas prácticas para la enseñanza virtual en la docencia universitaria.

A continuación detallamos cada uno de estos aspectos:

- Se presentan un elevado número de contenidos y recursos de información, la mayoría de carácter textual: programa de la asignatura, horarios, temario, manuales, etc.

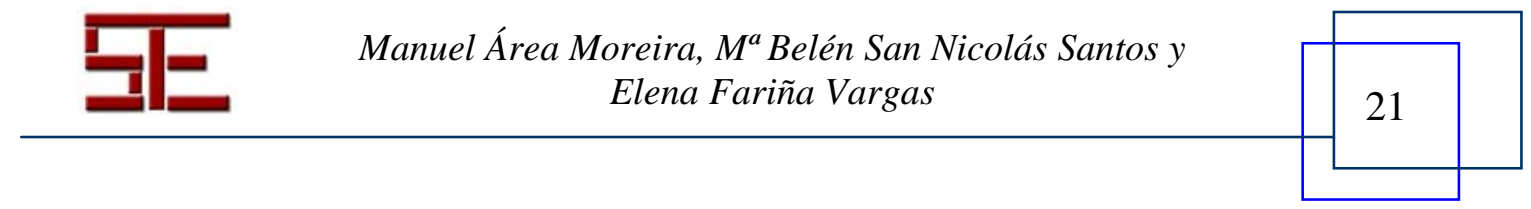




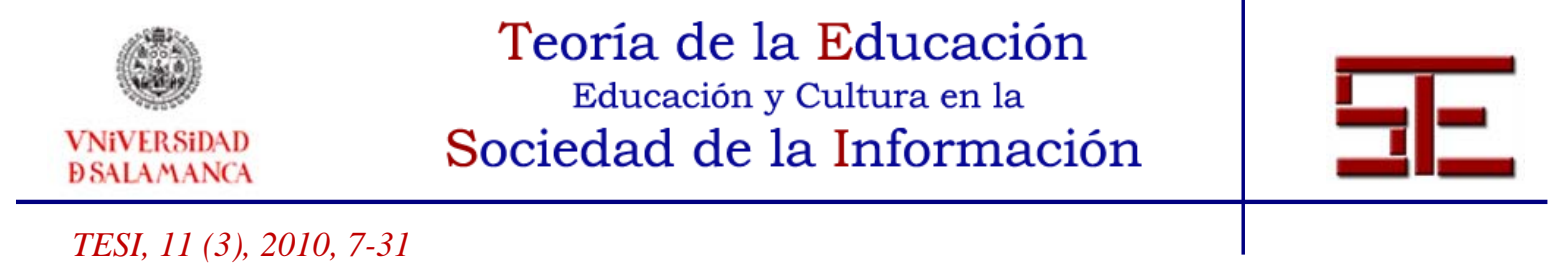

- En el aula virtual se incorporan numerosos enlaces de interés, clasificados en enlaces genéricos y jurídicos. El hecho de que se presenten estos vínculos en un bloque concreto y organizados en base a unos descriptores permiten al alumno encontrar de manera más sencilla y rápida los recursos que necesita.

- Al tratarse de una asignatura anual, el número de actividades que aparecen en el aula virtual es bastante elevado: casos de aplicación práctica, diario de la asignatura, debate, ensayos y reflexiones, glosario...

- Destaca entre las actividades una tarea realizada entre todos los alumnos del aula virtual, los cuales estaban organizados en pequeños grupos de trabajo. La actividad consistía en la creación de una página Web de la asignatura ${ }^{5}$.

Este espacio pretendía recoger información de la asignatura, vínculos y noticias interesantes, apuntes, casos prácticos, monografías de los temas, bibliografía, etc. A través del aula virtual, el profesor da las pautas necesarias a cada grupo de trabajo para que realicen las tareas encomendadas para la creación de la página Web. Los aspectos técnicos e informáticos no recaen en los alumnos, su función es la de crear, seleccionar y organizar los contenidos de la misma.

- En el aula virtual se creó un espacio o bloque específico para la comunicación y el debate, en el que aparecen foros, tablón de anuncios, cafetería, chat, línea directa y encuestas, donde hubo una importante participación.

- Además de evaluar el aprendizaje de los alumnos en el aula virtual, a través de la realización de las tareas y la participación en los foros, también el profesor evalúa la marcha de la asignatura a través de un entorno de enseñanza virtual. Para ello realiza varias encuestas y preguntas a sus alumnos sobre este nuevo espacio de enseñanza-aprendizaje.

Esta aula virtual además de transmitir contenidos y recursos de información, realizar diferentes actividades prácticas y experiencias reales, también es un espacio para el intercambio de informaciones y opiniones, así como para la colaboración sin limitaciones espacio-temporales.

\section{Asignatura: Estructura Económica Mundial I (2006-07)}

- Titulación en la que se imparte: Licenciado en Administración y Dirección de Empresas

- Número de profesores en el aula: 3

${ }^{5}$ La Web de la asignatura es la siguiente: http://webpages.ull.es/users/friorul/.

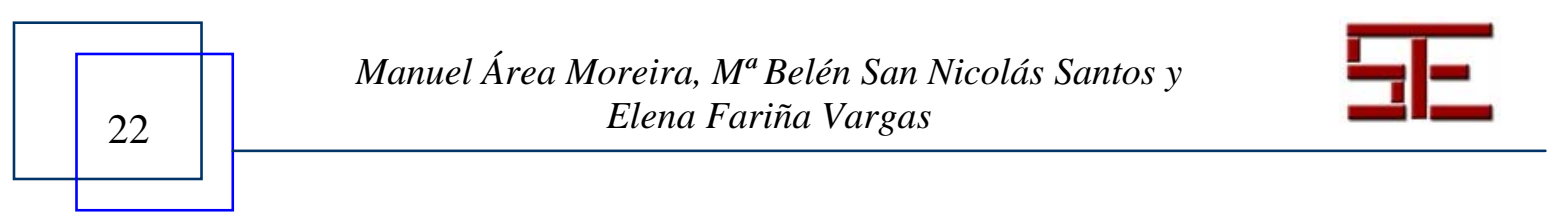




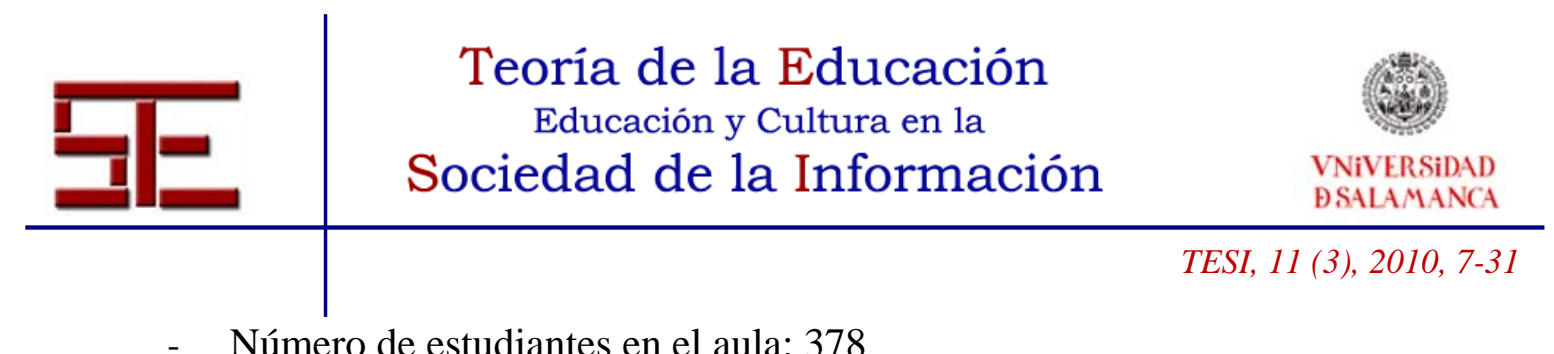

- $\quad$ Número de estudiantes en el aula: 378

El entorno virtual creado para la asignatura cuatrimestral de Estructura Económica Mundial I, durante el curso académico 2006-07, también es un espacio en el que se combinan varios ejemplos de buenas prácticas que han tenido éxito en el desarrollo de esta asignatura. A continuación se detalla cada una de estas experiencias:

- Esta aula virtual presenta una gran cantidad de información y recursos a sus alumnos, aunque la mayoría son de carácter textual. Los documentos que se incorporan al aula son: la presentación inicial de asignatura, el programa oficial de la misma, criterios de evaluación e informaciones para la realización de tareas y evaluaciones, numerosos artículos y lecturas de interés, esquemas y presentaciones multimedia, etc.

- La presentación de esta gran cantidad de recursos permite al alumno afianzar, profundizar e incluso ampliar los contenidos de la asignatura, además de poder acceder a ejemplificaciones de diferentes experiencias y proyectos.

- En el aula virtual se detallan numerosos enlaces de interés que se presentan en un bloque específico.

- En cuanto a las actividades, los profesores no se centran únicamente en la realización de actividades de evaluación automatizada, como pueden ser los cuestionarios de evaluación de contenidos teóricos y prácticos; este tipo de actividades facilita la tarea de corrección y el tiempo de dedicación a la evaluación es menor. Aunque el proceso de corrección es más lento y complicado, dado el elevado número de alumnos matriculados en este espacio, son bastantes comunes los cuestionarios de opinión, así como la redacción de ensayos y comentarios críticos.

- Destaca también de esta aula virtual la creación de un glosario con términos relacionados con la asignatura; era una tarea grupal que realizaron todos los alumnos del aula virtual (se alcanzaron 837 entradas).

- Son numerosas las consultas o preguntas concretas realizadas a los alumnos, podemos distinguir preguntas de carácter técnico (problemas en el acceso a Internet, problemas de acceso a la plataforma, problemas en el uso de las aplicaciones Moodle, etc.) y preguntas sobre la marcha de la asignatura. Se intenta conocer la opinión y los problemas de los alumnos en relación con la marcha de la asignatura.

- Los foros aparecen en varios aparatados del aula virtual, son muy numerosos y la participación de los alumnos también es bastante alta. Podemos distinguir entre dos tipos de foros: existen foros para dudas y problemas relacionados con la

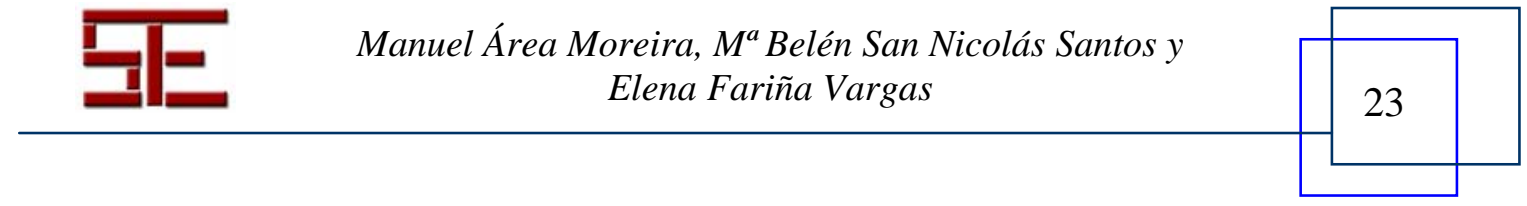




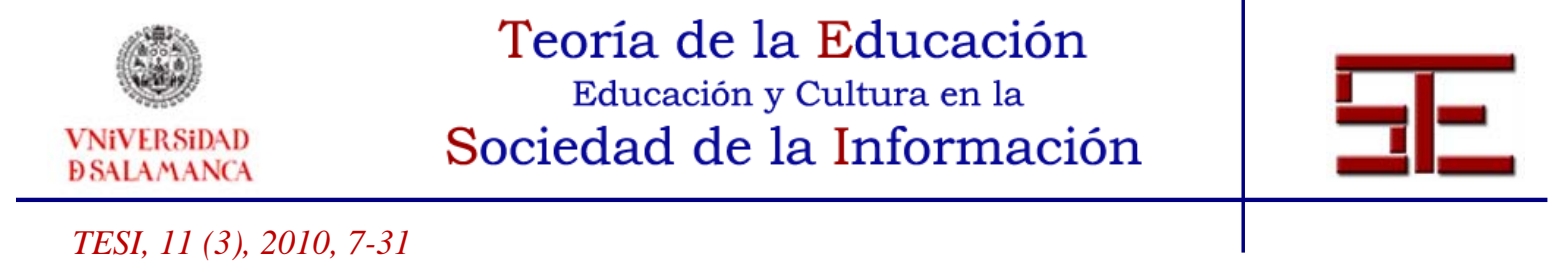

marcha de la asignatura y foros creados para el debate y la discusión de contenidos concretos del temario y temas económicos actuales. El elevado número de mensajes en los foros podría estar relacionado con la cantidad de alumnos matriculados en el aula, pero también con el tipo de preguntas y mensajes con los que los profesores comienzan los debates, así como las aportaciones que realizan para encauzar el tema y suscitar más respuestas.

- Los profesores del aula virtual, a través de los recursos de comunicación, han conseguido establecer un alto grado de comunicación e interacción entre el numeroso grupo de alumnos matriculados. A través de los ocho foros que fueron creados, los alumnos aportaron comentarios, ideas y soluciones que fueron valorados muy positivamente por los docentes.

Podemos considerar esta aula virtual como un espacio en el que se han combinado diferentes ejemplos de buenas prácticas que pueden ser un referente para la mejora. Primordialmente este espacio virtual ha sido concebido como un lugar para transmitir numerosos recursos y contenidos de información, realizar diferentes actividades prácticas y experiencias reales, pero también como un lugar para la comunicación, interacción y diálogo entre todos sus componentes, algo que también se refleja en las encuestas y preguntas de opinión que se realizan en numerosas ocasiones a los alumnos.

Asignatura: Las Tecnologías de la Información y la Comunicación en la Educación (2006-07)

- Titulación en la que se imparte: Licenciado en Pedagogía

- Número de profesores en el aula: 1

- $\quad$ Número de estudiantes en el aula: 77

El aula virtual de la asignatura de Las Tecnologías de la Información y la Comunicación, desarrollada durante el curso 2006-07, es otro de los espacios en los que podemos encontrar señas de buenas prácticas o actividades exitosas que pueden ser un referente para la creación de nuevos entornos virtuales.

A continuación se describen y analizan cuáles han sido esas prácticas y qué otros aspectos han permitido considerar este espacio como un ejemplo a tener en cuenta para la mejora de la docencia virtual.

- No se presentan muchos documentos textuales (programa de la asignatura y resultados de los cuestionarios), el resto de contenidos y recursos de información se encuentran en una sección creada con este fin: “La Biblioteca Digital”. En este apartado se recogen citas bibliográficas, lecturas, artículos y vínculos a pági-

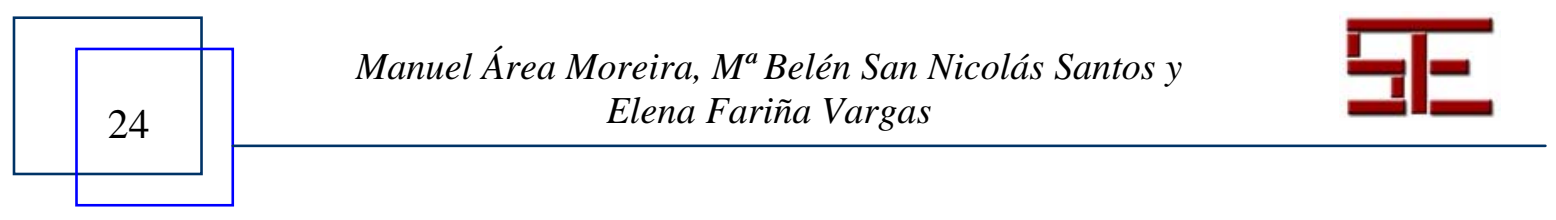




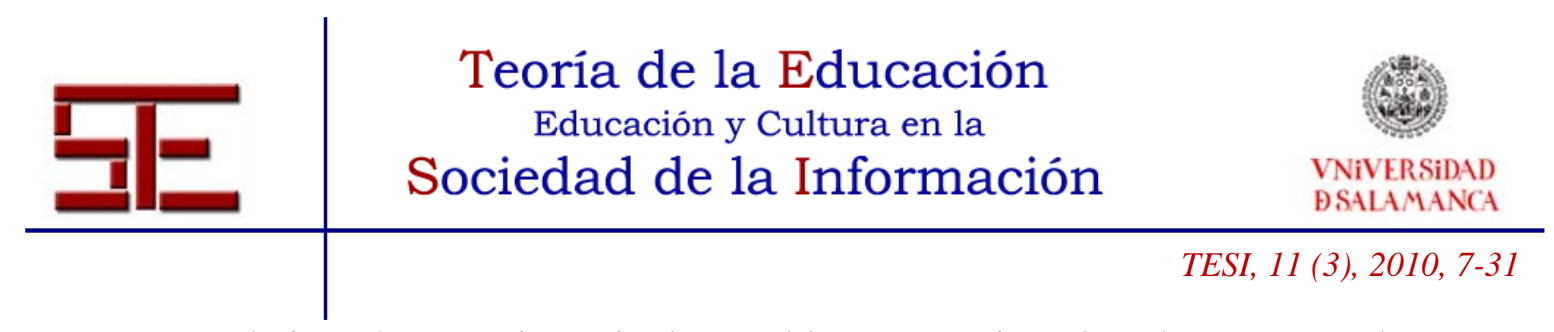

nas de interés. La existencia de este bloque permite a los alumnos acceder a una gran cantidad de información relacionada con los contenidos del temario, pero además pueden profundizar y ampliar sus conocimientos dado que la selección es bastante amplia. Además permiten al alumno encontrar de manera más sencilla y rápida los recursos que necesita.

- El aula virtual se encuentra organizada en función del tipo de actividad que se demanda a los alumnos. La estructura del aula es temática, pero no se tienen en cuenta los temas o contenidos de la asignatura, sino la tarea que los usuarios deben realizar: tu diario de clases, prácticas, Wikipedia de la asignatura, a la caza del tesoro y la biblioteca digital.

- Las actividades son muy variadas, pero destacan las tareas de búsqueda de información, en las que los alumnos deben desarrollar competencias de búsqueda, análisis, selección, actitud crítica, etc. Así como aprender a hacer búsquedas efectivas y de calidad a través de Internet. El resto de actividades también pretenden que el alumnado indague y construya su propio conocimiento, para ello el docente incorpora referencias bibliográficas, páginas Webs y experiencias reales para que elabore diferentes documentos, ensayos y trabajos sobre diferentes temáticas.

- Existen muchas actividades que se realizan de manera grupal, como la construcción de glosarios y la caza del tesoro. Ambas tareas requieren que los alumnos trabajen de manera conjunta para realizar una actividad en común, por ello en ambas secciones existe un foro para la organización del trabajo.

- La elaboración de diarios ayuda a los alumnos a recoger en un documento qué están aprendiendo, cómo y qué valoraciones hacen de estos aprendizajes.

- Otra de las actividades presentes en el aula virtual son los cuestionarios de valoración, las encuestas y las preguntas directas en los foros. Estos recursos son utilizados para conocer las opiniones de los alumnos sobre aspectos muy diversos.

- El profesor también realiza dos tipos de evaluaciones en el aula virtual, por un lado, evalúa el aprendizaje de los alumnos y, por otro, el funcionamiento y la marcha de la asignatura en la plataforma Moodle.

- Destacan considerablemente los foros. El foro de Novedades es un medio empleado por el profesor y son numerosos los mensajes que envía el tutor al aula para notificar a sus alumnos cualquier cambio, noticia o evento. Pero el foro que mayor participación alcanza es: "Pregunta y opina de la asignatura”. En este espacio se registraron un elevado número de mensajes y, en ocasiones, una gran cantidad de respuestas sobre un mismo tema. La participación de los alumnos es

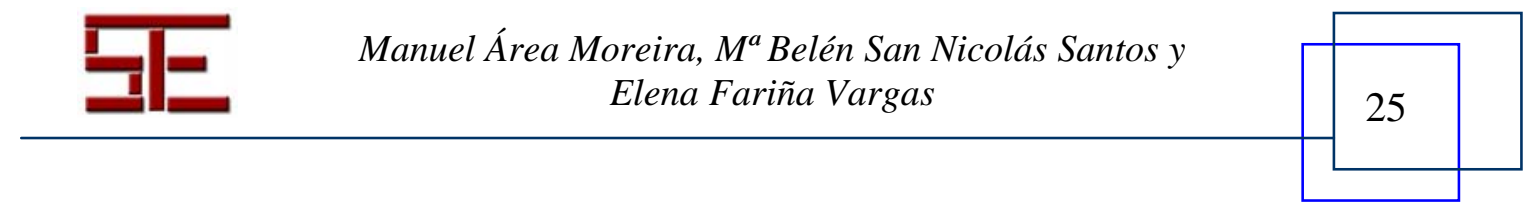




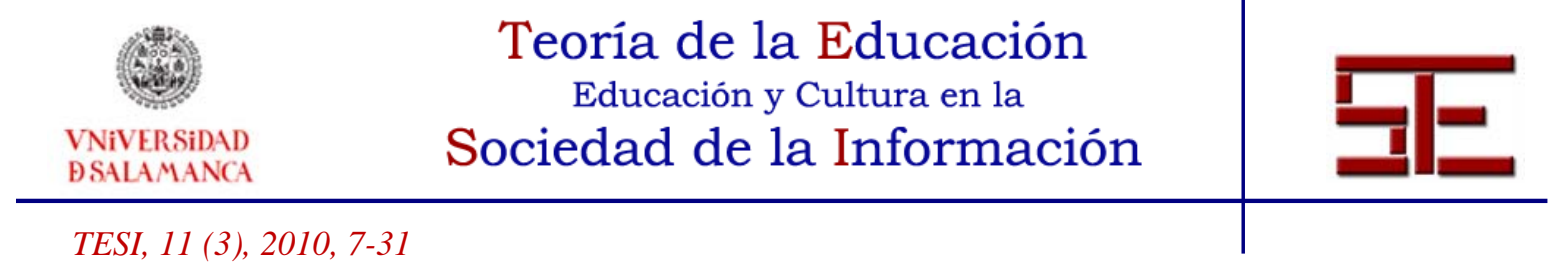

un aspecto valorado por el profesor, quien se encarga de potenciarla haciendo preguntas y realizando un seguimiento.

Esta aula virtual presenta un modelo pedagógico innovador donde además de transmitir contenidos y recursos de información, se centra en promover un aprendizaje experiencial y constructivista de los conocimientos de la materia disciplinar. Además potencia la comunicación y el intercambio de informaciones, opiniones y valoraciones entre todos los miembros de la clase.

\section{Campo de Ingeniería y Arquitectura}

\section{Asignatura: Análisis matemático IV (2005-06)}

- Titulación en la que se imparte: Licenciatura de Matemáticas

- Número de profesores en el aula: 1

- $\quad$ Número de estudiantes en el aula: 47

La profesora de esta asignatura incluye en el aula virtual una descripción general de la asignatura, así como introducciones de cada uno de los temas, además se especifican los objetivos de cada uno de ellos.

- Se presentan documentos de texto con las fórmulas en todos los temas, en el apartado de contenidos. Además de los contenidos en algunos de los temas cuelga documentos de ayuda, también con las mismas características textuales con las fórmulas matemáticas relacionadas con el contenido de la asignatura.

- También cuelga en ocasiones documentos complementarios con curiosidades.

- Como aspecto más novedoso la profesora cuelga en el aula un tutorial de utilización del programa Latex.

- Las actividades que más se desarrollan en esta aula virtual consisten en resolver problemas y el desarrollo y planificación de proyectos, este tipo de actividades está vinculado a la práctica de la asignatura.

- Destaca especialmente en esta aula virtual la utilización de los foros, la profesora se preocupa por resolver las dudas de los alumnos. Se desarrollan foros en cada uno de los temas, la participación en los mismos por parte del alumnado es muy variable pero la profesora responde a las cuestiones que plantean los alumnos en la mayor parte de las ocasiones.

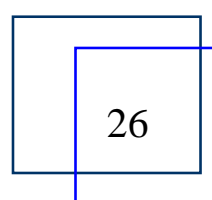

Manuel Área Moreira, $M^{a}$ Belén San Nicolás Santos y Elena Fariña Vargas 


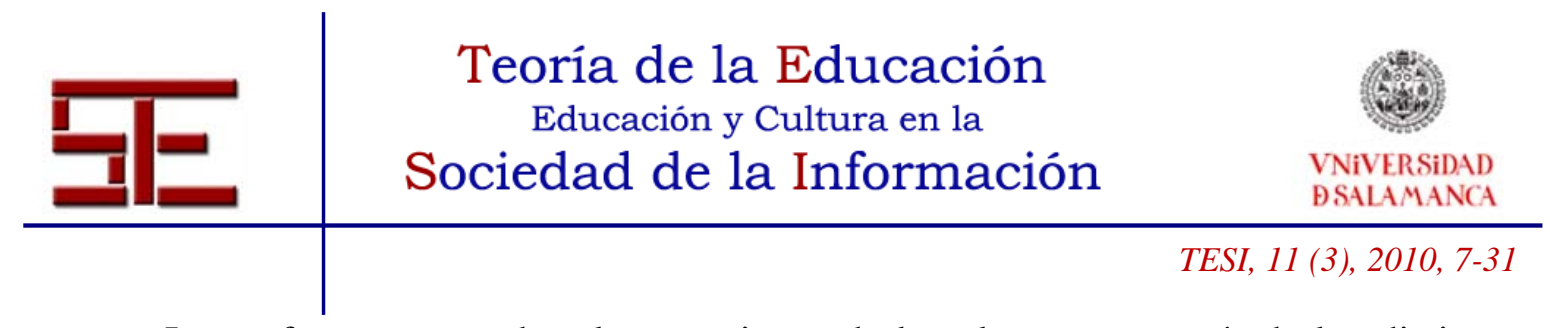

- La profesora responde a las cuestiones de los alumnos a través de los distintos foros.

Esta aula virtual concibe el espacio virtual como un medio para la transmisión de información, para la actividad del alumnado y como espacio para la comunicación e interacción social. Es especialmente destacable en esta aula virtual la preocupación de la profesora por resolver las dudas del alumnado, contesta a todas las preguntas y propone foros en cada uno de los temas.

\section{Asignatura: Sistemas de Interacción Hombre-Máquina (2006-07)}

- Titulación en la que se imparte: Ingeniero Técnico en Informática de Sistemas.

- Número de profesores en el aula: 4

- $\quad$ Número de estudiantes en el aula: 16

- Se presentan documentos textuales para todos los temas y en numerosas ocasiones presentaciones en Power Point, además de esquemas gráficos y mapas conceptuales.

- En cuanto a los elementos hipertextuales en cada uno de los bloques se ofrece un apartado con enlaces específicos.

- Se proponen distintos tipos de actividades, planificación y desarrollo de proyectos, resolución de ejercicios, cuestionarios, creación de glosarios, redacción de informes.

- Los proyectos que deben desarrollar los alumnos en esta asignatura giran en torno a las actividades prácticas de la misma. Diseñar un proyecto sobre la arquitectura de la información Card Sarting, diseñar una película con un formato específico.

- Los informes que los alumnos deben elaborar se centran en las siguientes prácticas: evaluación de páginas web, análisis de tareas HTA.

- Se plantean varios wikis sobre usabilidad, preguntas sobre diseño de interfaces, y repositorio de enlaces de recursos.

- En esta aula virtual se desarrollan un total de tres foros, el tablón de anuncios o foro del profesor, el foro de tutoría y un foro de aprendizaje, en estos dos últimos interviene tanto el profesor como el alumnado. Estos foros facilitan la comunicación y el feedback entre el profesorado y el alumnado.

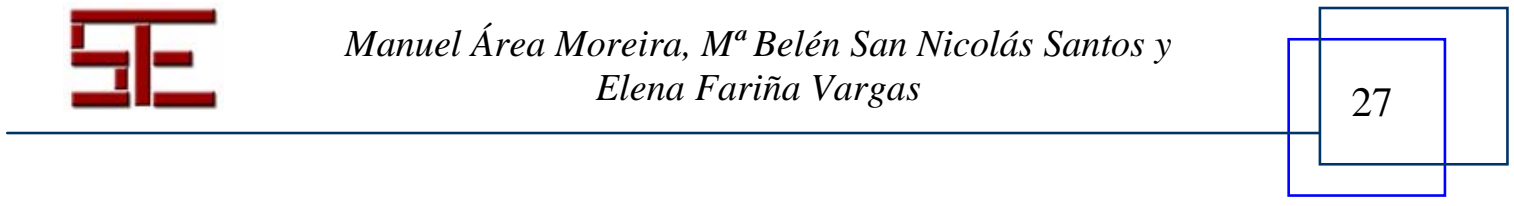




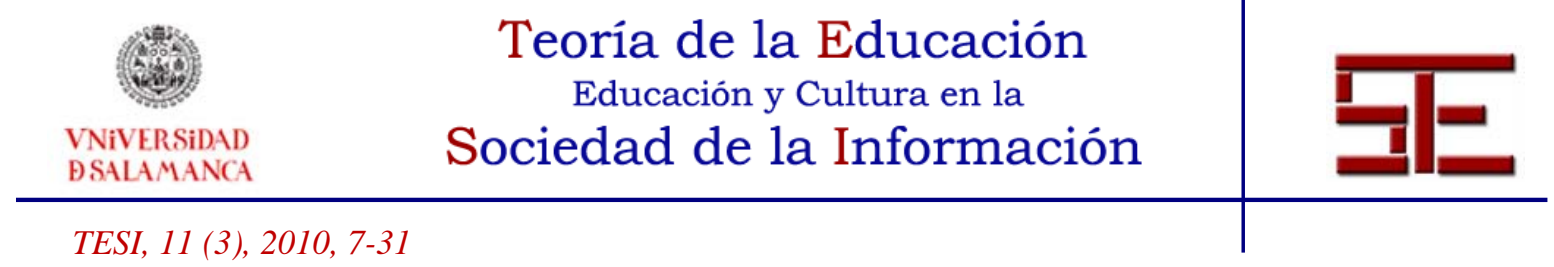

Esta aula virtual es un ejemplo de equilibrio entre los tres tipos de aulas virtuales, es un espacio para la transmisión de información, un espacio para la actividad del alumnado, y también un espacio para la comunicación e interacción social. Destacan algunas actividades, de proyecto y redacción de informes sobre actividades prácticas. Por otro lado, se proponen varios recursos de comunicación destinados a la tutorización a través del aula virtual.

Asignatura: Ingeniería térmica (2006-07)

- Titulación en la que se imparte: Ingeniero Técnico Industrial, en la especialidad de Mecánica

- $\quad$ Número de profesores en el aula: 1

- $\quad$ Número de estudiantes en el aula: 100

A pesar de la dificultad añadida de tener un elevado número de alumnos, en el aula virtual de esta asignatura se combinan distintos aspectos que hacen de la misma un aula equilibrada, se presentan documentos, se proponen actividades y se establece cierta comunicación. Estos hechos favorecen el desarrollo de la docencia y el aprendizaje a través de entornos virtuales.

- El profesor presenta documentos textuales de apoyo a la materia en todos los bloques, así como esquemas gráficos y resúmenes.

- En cuanto a la hipertextualidad, el profesor trata de acercar a los alumnos recursos útiles de carácter general, así como un libro on-line relacionado con la asignatura.

- Llama la atención que en esta aula el profesor cuelga un software para que los alumnos se lo puedan descargar y utilizarlo.

- Las actividades que se desarrollan en esta aula virtual se centran en la resolución de ejercicios, cuestionarios de evaluación de cada uno de los temas, creación de un glosario de la asignatura y redacción y desarrollo de informes sobre la resolución de un problema (en grupo).

- En esta aula virtual hay un total de 5 foros, la participación es muy desigual en cada uno de ellos. En el foro general relacionado con dudas técnicas sobre la asignatura sólo se produjeron tres mensajes y en el foro sobre dudas y sugerencias se produjeron un total de 31 mensajes.

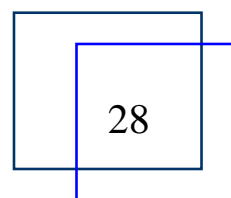

Manuel Área Moreira, $M^{a}$ Belén San Nicolás Santos y Elena Fariña Vargas 


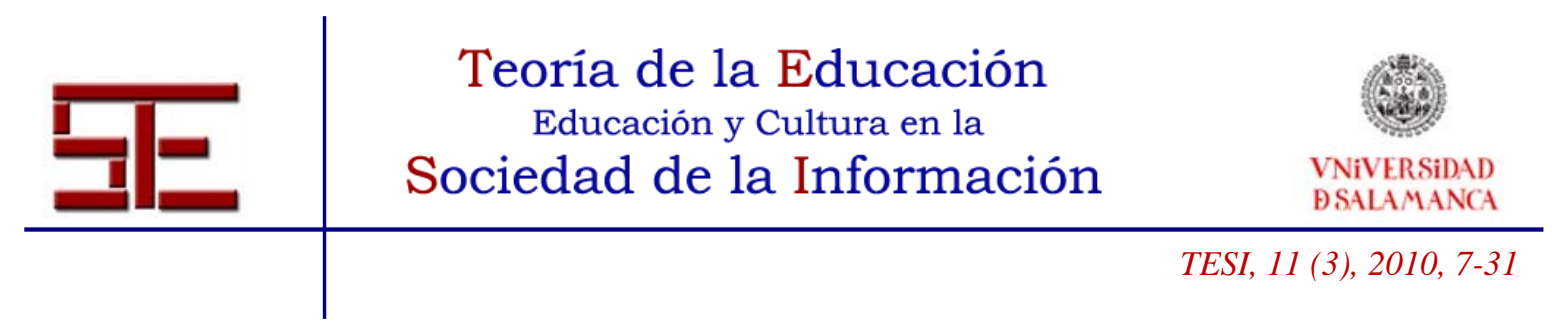

Teniendo en cuenta el feedback que se produce tanto en los foros que se mantienen activos como en los documentos de las correcciones que el profesor cuelga en el aula virtual, se puede decir que existe una buena comunicación entre el profesorado y el alumnado a través del aula virtual que favorece el desarrollo de la asignatura. Esta aula presenta muchos archivos para que los alumnos se los descarguen y los impriman, además de ejercicios prácticos y resueltos. Por otro lado, también existe comunicación entre el profesor y los alumnos. Podemos considerar esta aula virtual un ejemplo de buena práctica que combina los aspectos de transmisión de información, de propuesta de actividades y de interacción y comunicación. Se plantean actividades diversas, tareas principalmente de índole práctica de resolución de ejercicios, pero también glosarios y proyectos, además de cuestionarios de evaluación.

El profesor tutoriza a los alumnos a través de los foros y por medio de las correcciones de las tareas, que cuelga también en el aula virtual. También se plantean sesiones de "resolución tutorizada de problemas" que consisten en resolver problemas en pequeños grupos y redactar un informe sobre el análisis de la resolución. Destaca de la evaluación que los alumnos tienen a su disposición los exámenes con las soluciones así como las calificaciones que han obtenido, para que puedan consultarlas.

\section{7.- CONCLUSIONES}

Los ejemplos de aulas virtuales identificados superan modelos reduccionistas de la docencia basados en la mera transmisión de información mediante el hecho de "colgar" apuntes (como si se dejaran en una fotocopiadora) o como repositorio de ejercicios que los estudiantes debieran cumplimentar. Por el contrario, las aulas virtuales descritas se caracterizan porque incorporan y desarrollan tres ámbitos o dimensiones clave de los procesos de enseñanza-aprendizaje en el e-learning:

a) presentan el contenido informativo a los estudiantes mediante distintas modalidades o formatos simbólicos -documentos textuales, hipertextos, presentaciones multimedia, esquemas/mapas conceptuales;

b) ofrecen una propuesta de actividades variada para que sean realizadas por los propios estudiantes de modo que éstos desarrollen experiencias de aprendizaje en torno a dichos contenidos; $y$

c) desarrollan procesos comunicativos variados, fluidos y constantes entre el profesor y sus alumnos así como entre los propios estudiantes a lo largo del tiempo de duración de impartición de la asignatura.

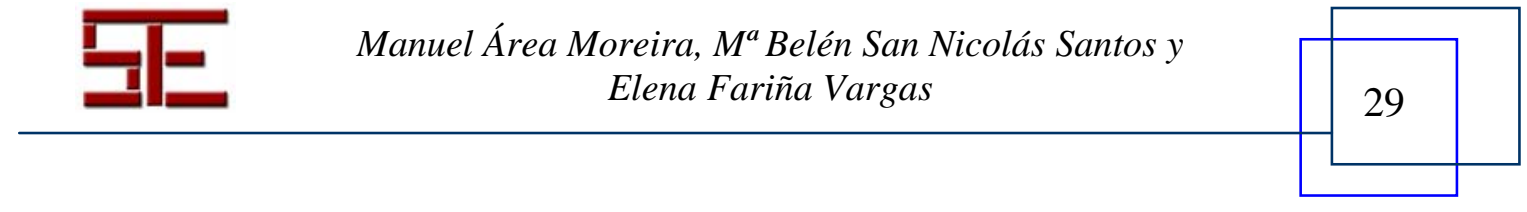




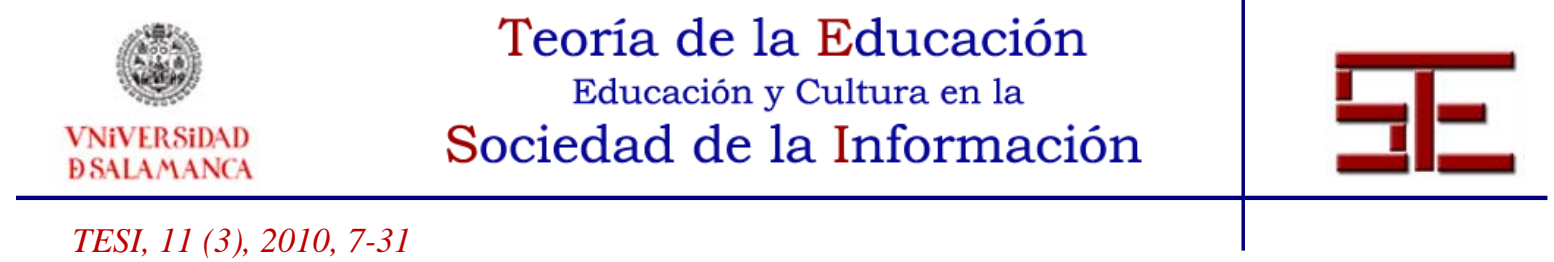

En este sentido, en la mayor parte de estos ejemplos subyace una visión del aprendizaje basada en la actividad del estudiante y en la construcción del conocimiento por parte de los mismos más que en un modelo de aula virtual utilizada con la finalidad casi exclusiva de ser un espacio para la transmisión de información. Las aulas virtuales descritas anteriormente reflejan un notorio esfuerzo creativo y de innovación docente por parte de los profesores responsables de las mismas que se traduce en la creación de materiales multimedia, en la propuesta de distintas tareas de aprendizaje y, sobre todo, en una gran actividad de interacción y comunicación social a través de foros.

Consideramos que estas aulas virtuales debieran ser utilizadas como ejemplos para generalizar, de manera que sirvan de referente en la formación del profesorado y para la promoción de modelos educativos innovadores y, en consecuencia, sugerimos que en los procesos y actividades formativas destinadas a que el profesorado universitario desarrolle modelos de docencia de blended learning las aulas anteriormente descritas pueden ser utilizadas como casos de estudio y debate.

Finalmente, indicamos que sería interesante seguir desarrollando nuevos análisis en esta dirección para profundizar en el conocimiento de las razones y explicaciones que llevan a estos docentes a generar entornos virtuales innovadores para su docencia. En este sentido, una posible investigación futura podría consistir en realizar un seguimiento más pormenorizado de la evolución de estas aulas virtuales explorando simultáneamente tanto las perspectivas y opiniones del profesorado como de los estudiantes mediante otras técnicas como las entrevistas, cuestionarios o discusiones grupales.

\section{8.- BIBLIOGRAFÍA}

Área, M. (2005). Internet y la calidad de la educación superior en la perspectiva de la Convergencia Europea. Revista Española de Pedagogía (REP), Año LXIII, 230, eneromayo.

Área, M. (coord.) (2007). Monográfico: La docencia virtual en las universidades presenciales. Revista Iberoamericana de Educación a Distancia (RIED), 10(12), diciembre Área, M. et al. (2002.: El campus virtual de la Universidad de La Laguna. Comunicación y Pedagogía, 184, 8-13.

Área, M. y Adell, J. (2009). ELearning: Enseñar y Aprender en Espacios Virtuales. En J. de Pablos (Coord.), La tecnología educativa en el siglo XXI. Málaga: Editorial Aljibe. Barajas, M. y Álvarez, B. (eds.) (2003). La Tecnología Educativa en la enseñanza superior: entornos virtuales de aprendizaje. Madrid: Ed. McGraw-Hill.

Barbera, E. (coord.) (2008). Cómo valorar la calidad de la enseñanza basada en las TIC. Pautas e instrumentos de análisis. Barcelona: Grao.

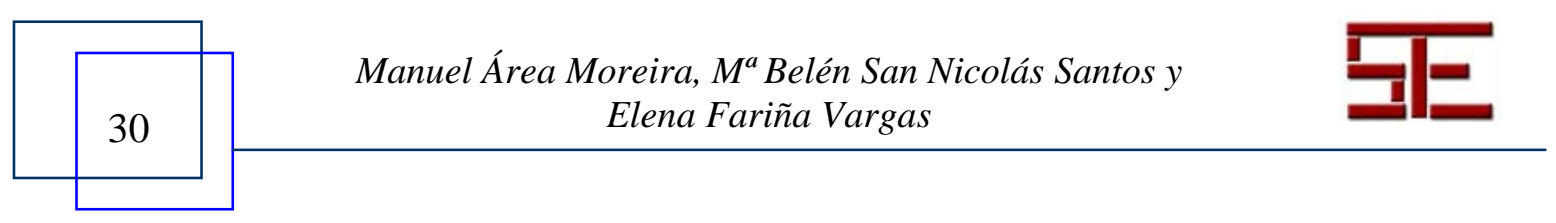




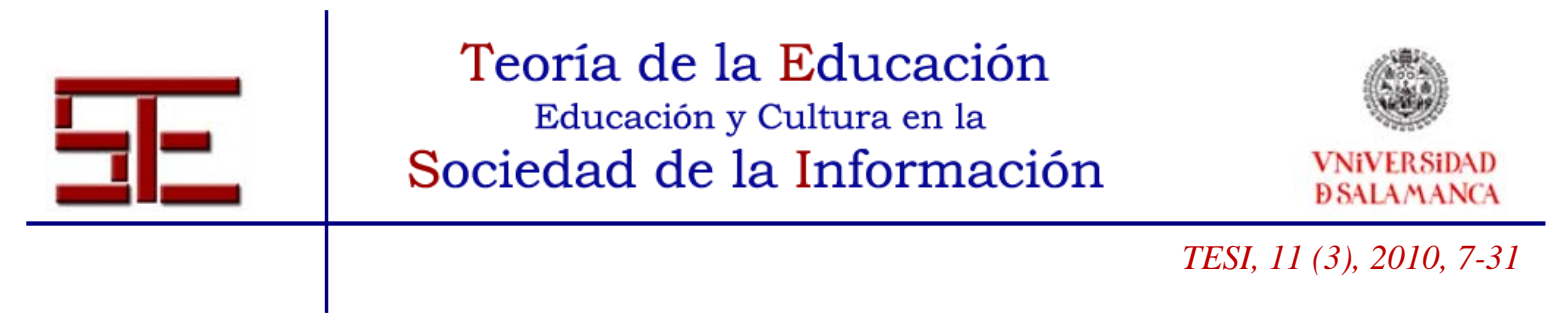

Cebrián de la Serna, M. (2003). Enseñanza virtual para la innovación universitaria. Madrid: Narcea Ed.

Chickering, A. W. \& Gamson, Z. F. (1987). Seven Principles For Good Practice In Undergraduate Education. The American Association for Higher Education Bulletin, March.

De Pablos, J. y Jiménez, R. (2007). Modelos de buenas prácticas con TIC apoyados en las políticas educativas. Comunicación y Pedagogía, 222, 36-41.

Epper, R. M. \& Bates, A. W. (2004). Enseñar al profesorado cómo utilizar la tecnología. Buenas prácticas de instituciones líderes. Barcelona: Editorial UOC.

García, L., Ruiz, M. y Domínguez, D. (2007). De la educación a distancia a la educación virtual. Barcelona: Ariel.

González, T. (2007). El concepto de buenas prácticas. Origen y desarrollo. Comunicación y Pedagogía, 222, 32-35.

Landetta, A. (2008). Buenas prácticas de E-learning. Madrid: Anced.

Stephenson, J. (2005). Definitions of indicators of quality on the application of ICT to University Teaching. Disponible en http://www.johnstephenson.net/qualonlinehe.pdf.

Para citar el presente artículo puede utilizar la siguiente referencia:

Área Moreira, M., San Nicolás Santos, Mª B. y Fariña Vargas, E.: (2010). “Buenas prácticas de aulas virtuales en la docencia universitaria presencial”. En De Pablos Pons, J. (Coord.) Buenas prácticas de enseñanza con TIC [monográfico en línea]. Revista Electrónica Teoría de la Educación: Educación y Cultura en la Sociedad de la Información. Vol. 11, $\mathrm{n}^{\circ}$ 1. Universidad de Salamanca, pp. 7-31. [Fecha de consulta: dd/mm/aaaa]. http://revistatesi.usal.es/ revistas_trabajo/index.php/revistatesi/article/view/5787/5817 ISSN: 1138-9737

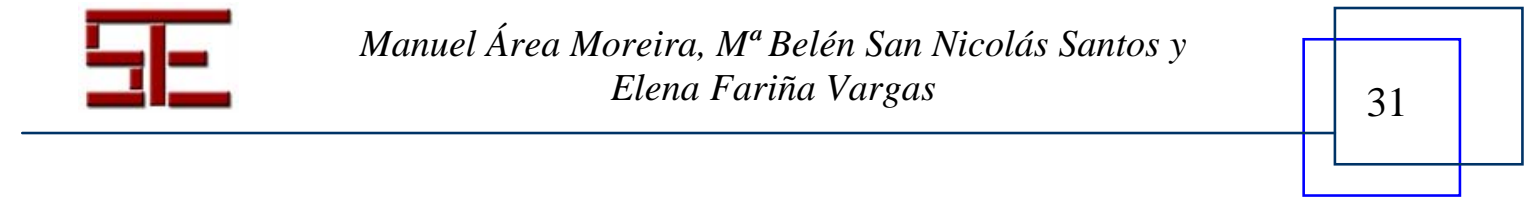

